\title{
Exploring the Self-Reported ICT Skill Levels of Undergraduate Science Students
}

\author{
Dirk Heerwegh \\ Leuven Statistics Research \\ Centre (LStat), \\ University of Leuven, \\ Leuven, Belgium \\ dirk.heerwegh@Istat.kuleuven.be
}

\author{
Kurt De Wit \\ Data Management Unit, \\ University of Leuven, \\ Leuven, Belgium
}

kurt.dewit@kuleuven.be

\author{
Jef C. Verhoeven \\ Centre for Sociological Research, University of Leuven, \\ Leuven, Belgium \\ jef.verhoeven@soc.kuleuven.be
}

\begin{abstract}
Computers have taken an important place in the training of science students and in the professional life of scientists. It is often taken for granted that most students have mastered basic Information and Communication Technologies (ICT) skills; however, it has been shown that not all students are equally proficient in this regard. Starting from theories of socialization and technology acceptance we report how we constructed a structural equation model (SEM) to explore the variance in the basic ICT skill levels of science students. We also present the results of a test of this model with university bachelor's science students. Basic ICT skills were measured using a new, elaborate instrument allowing students to rate their skills in detail. Our results show that science students score high on basic ICT skills and that our SEM explains a large part of the variation in the ICT skill levels of these students. The most explanatory power is coming from four variables: the perceived ease of use and the perceived usefulness of a personal computer, the anxiety for using a personal computer, and students' belief that ICT is necessary for scientific research.
\end{abstract}

Keywords: survey, ICT skills, computer literacy, science students, technology acceptance model, TAM, higher education, structural equa-

Material published as part of this publication, either on-line or in print, is copyrighted by the Informing Science Institute. Permission to make digital or paper copy of part or all of these works for personal or classroom use is granted without fee provided that the copies are not made or distributed for profit or commercial advantage AND that copies 1) bear this notice in full and 2) give the full citation on the first page. It is permissible to abstract these works so long as credit is given. To copy in all other cases or to republish or to post on a server or to redistribute to lists requires specific permission and payment of a fee. Contact Publisher@InformingScience.org to request redistribution permission. tion model, confirmatory factor analysis

\section{Introduction}

Science, technology, engineering, and mathematics (STEM) students in many countries constitute a relatively small group compared with those studying the humanities or biomedical sciences (OECD, 2015). The relatively small number of science students is the result 
of a cooling-off process that starts in secondary school. Several studies (George, 2006; Cheryan \& Plaut, 2010; Bøe, Henriksen, Lyons, \& Schreiner, 2011; Venville, Rennie, Hanbury, \& Longnecker, 2013) have shown that the motivation of people to study sciences declines during their progress through secondary school, especially for female students (Sadler, Sonnert, Hazari, \& Tai, 2012). University students who take science as a subject choose it because they are interested in science and/or believe that they are good at it, and consider that financial rewards and the prestige of science are less important than a passion for knowledge (Venville et al., 2013). However, extrinsic motivation has a meaning for those who choose to study science, as was shown by Domene, Socholotiuk, and Woitowicz (2011). For example, Venville et al. (2013) also observed the influence of science classes in secondary schools and science teachers in particular. The choice to study science is also influenced by gender differences. The sciences have been - and still are - male dominated, which does not generate a more positive attitude toward science among female students (Matsui, Ikeda, \& Ohnishi, 1989; George, 2006; Goyette \& Mullen, 2006; Bøe \& Henriksen, 2013).

In the last three decades, the development of science has been accompanied by, and boosted by, an explosion of computer power. Nowadays it has become hard to imagine doing science without using computers. This is an additional challenge for students who want to study science, but it also creates opportunities. Moreover, it offers new instruments (such as computer-aided mathematical systems (CMS) and computer-aided instruction (CAI)) and methods to bring science closer to the students (Smirnov \& Bogun, 2010). Studies have demonstrated that teaching methods involving computer-assisted learning schemes have a positive influence on the transfer of science to students in general (Russell, Lucas, \& McRobbie, 2003; Schaal, Bogner, \& Girwidz, 2010; Donnelly, O'Reilly, \& McGarr, 2013; Ridgewell \& Exley, 2011; Chen, Chang, Lai, \& Tsai, 2014; Rabaya'h, 2010) and STEM students in particular (Kubiatko \& Vlckova, 2010; Smirnov \& Bogun, 2010; Spieza, 2010; Mandrikas et al., 2013; Al-Rsa'i, 2013; Çalik, Özsevgeç, Ebenezer, Artun, \& Küçük, 2014). In addition, better mastery of basic ICT skills has a positive effect with regard to the acceptance of mobile learning (Mac Callum \& Jeffrey, 2013; Mac Callum, Jeffrey \& Kinshuk, 2014). It is therefore reasonable to state that computers have taken an important place in the professional life of scientists, as well as in the training of science students. From this, it could be expected that science students, generally speaking, will have good knowledge of the basic ICT skills, because they will need this for their studies and their future professional life. Notwithstanding the expectation that most students will have sufficiently mastered basic ICT skills in order to study in school, it has been shown that not all students are equally proficient in this regard (Kaminski, Switzer, \& Gloeckner, 2009; Verhoeven, Heerwegh \& De Wit, 2010; De Wit, Heerwegh $\&$ Verhoeven, 2012). In this article, we propose a model exploring the differences between students in (self-perceived) ICT proficiency. Starting from theories of socialization and technology acceptance (section 'Theory'), we use structural equation modelling to develop an explanatory model with ICT skill level as the dependent variable (section 'Methods'). We also present the results of a test of this model (section 'Results') with a sample of undergraduate science students in a large university. In the concluding sections, we discuss our findings and draw conclusions regarding the usefulness of our model to explore differences in (self-reported) ICT skill levels.

\section{Theory}

Ever since Mark Prensky's influential paper (2001), many authors consider children born this century to be "digital natives". The educational situation of contemporary youth is typified as being continuously surrounded by a multitude of digital devices. Children grow up in a world in which personal computers (PCs), smartphones, MP3 players, tablets, and so forth, are omnipresent. It is this special educational experience of contemporary students that inspired us to focus on the educational situation for the mastery of basic ICT skills. From a sociological viewpoint, education can be seen as a socialization process. Socialization is a key concept in many sociological 
paradigms for understanding why people act the way they do. Georg Simmel (1910, p. 377) viewed the "consciousness of associating or of being socialized" as essential to make society possible. Other prominent sociologists also gave the concept of socialization an important place in their theories; for example, the social behaviorist G. H. Mead (1972, p. 1-25; 1974), the functionalist Talcott Parsons (1964) and, in phenomenology, Berger and Luckmann (1966).

In order to build our model to explain the differences in ICT skill levels among science students, we therefore start from the socialization theory of the pragmatist Tamotsu Shibutani (1986), and a theory about the acceptance of new technologies (TAM) suggested by Fred D. Davis (1989). This theory offers a clear road for the empirical study of the self-reported ICT skills levels of science students. Successively we will discuss the meaning of socialization, the meaning of a digital literate, and the meaning of the family, gender, the school, and TAM for the proficiency in basic ICT skills.

Socialization is defined by Shibutani $(1986$, p. 155) as "the acquisition of those norms that enable a newcomer to act in concert with others". This is a learning process that takes place in all situations in which people function. Socialization happens through participation in social interaction. Children learn how to act from other children and from adults. Their friends, parents, siblings, teachers, and so forth, are models for future behavior, or they reinforce socially-accepted behavior. If children act properly, they will not be punished, but instead rewarded. If their behavior deviates from the norms, punishment might be applied to bring them into line with what is expected of them. By behaving in certain ways and by being rewarded or penalized for their acts in line with the roles that are expected of them, children learn to play social roles. Social interaction in the family, on the street, at school, and so forth, allows children (and, in fact, any newcomers in a social situation) to become accepted role players. Many roles are learned in informal situations, but at certain times they are also transmitted formally. For example, playing the role of a good student is not only transferred by friends, but also by parents and teachers. This means that roles call for different expectations among the other actors and consequently also for different punishments or rewards by a significant other. If a person has to simultaneously play different roles with opposing expectations, this might lead to role conflicts. In what follows, we study the conditions that might be influential for the socialization of students who are supposed to be (or to become) digital literates, proficient in the basic ICT skills.

The prime objective of this study is to see how well STEM students have mastered some basic ICT skills. Asking this question suggests that STEM students belong to a group that could be called digital literates. Students in contemporary societies are supposed to be socialized into the role of a digital literate and to play this role properly. Other research shows that these expectations exist in universities and on the labor market as well. Of particular interest in this respect is the research report Reaching Students: What Research Says about Effective Instruction in Undergraduate Science and Engineering (Kober, 2014). Throughout this report it is shown how engineering students may benefit from new ways of instruction in which computer-based instruction is included. The report states, "[c]omputers and Web-based technologies are essential to the practice of science and engineering, and their applications to undergraduate education in these disciplines are innumerable" (Kober, 2014, p. 148). This thesis is followed by examples where, among others, use is made of blogs, social media, and web-based simulations. Smirnov and Bogun (2010) believe that, if engineering students would be digital literates, it would be possible to offer them a better training in science, because ICT support might then increase their motivation to study science. Based on their research they conclude that their hypothesis about "... the significance of the integrated approach to interaction of science and mathematics with ICT in engineering education" (Smirnov \& Bogun, 2010, p. 1406) has been partly confirmed. This would not be possible if students were not digital literates. Summers and Vlosky (2001) observed in an agriculture faculty that students and faculty were convinced that both traditional and computer-based 
teaching methods should go together and that computer-based technology in the classroom might be later very important for the students' competitiveness on the labor market. In a direct research of the labor market, Graham (2001) observed among employers of agriculture graduates that they expected them to know how to get access to the Internet and how to use it, and a good knowledge of word processing, spreadsheets, database, and graphics.

These research results with regard to STEM students may raise the question whether in modern society these students need to be more capable to apply basic ICT skills, or to apply different ICT skills, than other students. We would argue that all students need these skills, but that it depends on the discipline which skills are important in that particular domain. We would refer in this respect to the ideas of Iwona Miliszewska (2008). She stresses that in an Information Age all graduates should be able "to demonstrate at least the general ICT skills" (Miliszewska, 2008, p. 105) and she mentions two categories: (1) the use of software and hardware tools; and (2) the responsible use of Internet services. Each graduate should have some knowledge of these basics, but the level of expertise might be different depending on the discipline. For instance, a good knowledge of using spreadsheets is probably more rewarding for a science student than a humanities student, but both would have advantage when they have a good knowledge of presentation software.

Digital literacy has been given many definitions and many names. From a literature review, Ilomäki, Paavola, Lakkala, and Kantosalo (2014) concluded that digital competence should refer not only to technical competence and the capacity to use digital technologies, but also to the competence to evaluate critically these technologies and the motivation to participate in this ICT culture. In this article, we focus on the competence to use basic ICT skills. However, this concept also lacks a generally accepted definition. Therefore, we follow the opinions of two reputed institutions, the US Committee on Information Technology Literacy (1999) and the European Computer Driving License (ECDL) Foundation (ECDL, 2010) to define what a digital literate is supposed to be able to accomplish with ICT instruments. In the Methods section we will present in more detail how we defined and measured these basic ICT skills in seven skills areas (PC maintenance, word processing, the use of spreadsheets, databases, presentation software, Internet browsing, and communication), insofar as these skills are applied using a PC.

In order to become a digital literate, a student progresses through a socialization process that starts in the nuclear family. In recent decades, it has become common for a large number of Western families to have a computer at home and, more recently, even to have tablets and smart phones in addition. Many children therefore learn from a young age how to use computers and other ICT instruments. They learn by experience, and by imitating their parents, siblings, or friends. This might mean that students have been socialized from a young age to become digitally literate. Because digital instruments are present to a greater extent now than they were two decades ago, it can be expected that youngsters will attain higher scores for ICT proficiency than older people. Van Deursen and van Dijk (2015), for example, researched a Dutch population of people over 16 and concluded that younger actors have better Internet skills than older actors. In addition, Aslanidou and Menexes (2008) observed that the youngest group of students in secondary schools uses the Internet more frequently than the older group. Using the Czech data from the Program for International Student Assessment (PISA) 2006, Kubiatko and Vlckova (2010) found that students who had used computers the longest attained higher scores for a test of ICT knowledge. Chowdhury, Gibb, and Landoni (2011) came to the conclusion that experience of university staff members of searching for information on the Internet depended on their age. From these studies, we can derive that age might have some influence on mastering ICT skills. We hypothesize that the younger a student, the more ICT proficient he or she will be. However, not only age itself, but also - or even more so - the age at the time of first PC experience might influence ICT proficiency. We therefore presume that students who had their first experience of ICT at a young age will score higher on ICT skills than students who started later. 
Heerwegh, De Wit, \& Verhoeven

This is obviously a consequence of what parents allow their children to do with ICT instruments and whether students are able to use these at home. The opportunity to have access to these instruments and to use them freely is more prevalent in families where the parents have a high socioeconomic status and/or a high level of education. Data from PISA 2006 concerning 15 year olds, confirms that greater family wealth, a high education level, and high socioeconomic parental status create a family life where more computer use is possible for these children (Spieza, 2010; Zhong, 2011). The positive link between socioeconomic status and self-reported ICT skills has been confirmed for children in both secondary education (Zhao, Lu, Huang, \& Wang, 2010; Zhong, 2011) and primary education (Vekiri \& Chronaki, 2008; Vekiri, 2010a). The substantial impact of the nuclear family on PC use is also a consequence of the fact that students use a PC more at home than at school (Rabaya'h, 2010). Computers are more accessible at home than in school and research has shown that adolescents learn more by using a PC at home than in formal ICT classes (Zhong, 2011).

Since the family environment is of major importance for transmitting culture, we hypothesize that families where parents use a PC at home and/or at work will be more open to the use of a PC by their children and might create a situation that is beneficial for learning ICT skills. Families not only provide social status to young people, but also educate children to become appropriate role players as a girl or boy, and they do this within the cultural framework of a particular society. Therefore, the male and the female roles might differ between different societies. This could have an influence on the attitude of people toward ICT and on behavior connected with ICT (Madigan, Goodfellow, \& Stone, 2007). In Western societies, a masculine culture is often constructed with regard to ICT. As a consequence, parents see computers as being of less interest to girls, thus contributing to less interest in computers by women. If women become professionally interested in computers, they are more likely to choose jobs where computers are used to play a care role, in line with traditional expectations of women (for example, ICT in education). Pechtelidis, Kosma, and Chronaki (2015) described this process as a clever adaptation by women to the expectations of a male-dominated field, while at the same time maintaining traditional family roles. Many publications have shown that girls and women are less keen to work with a computer or to apply ICT programs or ICT instruments compared with boys and men (Volman \& van Eck, 2001; Losh, 2004; Becker, 2006; Madigan et al., 2007; Kubiatko, 2010; Zhao et al., 2010; van Deursen \& van Dijk, 2015). However, research (Bovée, Voogt, \& Meelissen, 2007; Wang, Wu, \& Wang, 2009; Verhoeven et al., 2010; De Wit et al., 2012) has also demonstrated that the gap between male and female actors is not common to all types of use of ICT applications and not in all countries (Spiezia, 2010), and that women (researchers) are more proficient in some ICT skills than men are (Chowdhury et al., 2011). With regard to the link between gender and ICT and research in secondary education, Hohlfeld, Ritzhaupt, and Barron (2013) even concluded "that the gender gap for demonstrated technology skills has closed", although this observation was not confirmed by the longitudinal study among adults by van Deursen and van Dijk (2015). In sum, relevant literature is inconclusive on whether or not the gender gap is closing, but nevertheless gender still plays a role with regard to specific ICT skills and attitudes toward ICT. Therefore, we include gender in our model as an explanatory factor.

In addition to socialization at home, students might also become more open to ICT when the use of computers is stimulated at school. Research offers a mixed picture regarding the influence of formal ICT training in schools. Zhao et al. (2010) observed that the school has a weak influence on the Internet self-efficacy of students in secondary education. Vekiri (2010b) found a relatively positive attitude of students (male and female) toward ICT lessons and a weak but significant positive correlation between class instruction for ICT and the self-efficacy beliefs of boys and girls. Other observations in 2004, 2005, and 2009 (Verhoeven et al., 2010; De Wit et al., 2012) have confirmed that university freshers who took ICT classes in secondary school considered themselves more capable of applying some ICT skills, but not all. Therefore, we examine in our 
model whether having taken ICT courses in secondary school has an influence on the ICT skills of bachelor's students.

Up to this point, we have sketched the structural contours in which socialization into a skillful ICT actor takes place. We assume that the socialization context does not have a direct influence on the ICT skills of students, but instead will first affect attitudes to ICT, which will subsequently have an influence on ICT skills. To check this, we use the Technology Acceptance Model (TAM) created by Davis (1989). This model has been used and adapted by Venkatesh, Morris, Davis, and Davis (2003) and many others (e.g., Nair \& Das, 2011; Maneschijn, Botha, \& van Biljon, 2013).

We use four variables as they are developed by Fred E. Davis and in the more expanded model by Venkatesh et al. (2003). As defined by Davis (1989), "perceived usefulness" refers to the expectation of an actor that the use of a technology will contribute to better performance of his or her job in an organization, and "perceived ease of use" to the expectation of an actor that the application of a technology is feasible without too much effort. Davis elucidates the meaning of these concepts through the link with Bandura's self-efficacy theory. Bandura (1982, p. 122) defines perceived self-efficacy as "judgments of how well one can execute courses of action required to deal with prospective situations." This concept is, in Davis' terminology, similar to the perceived ease of use. But besides judgements about our self-efficacy, Bandura also mentions outcome judgements. These are judgements made by the actor about future acts taking into account an act may have had success before. This concept is similar to the idea of perceived usefulness. The third variable we use is "anxiety", which can lead to fear and stress among computer users. In the context of our research, this refers to the anxiety of actors regarding the use of a personal computer (Venkatesh et al., 2003; Verhoeven et al., 2010; Ursavaş \& Teo, 2011; Celik \& Yesilyurt; 2013). Although there might be a relationship between anxiety for using a computer and perceived ease of use of a computer, we have studied both variables separately. The fourth variable, "negative behavior", refers to behavior that expresses a negative attitude toward the use of a computer. For instance, students might look for other procedures to do a task than using a computer. Or they might refuse the task if it has to be done by using a computer. We will observe this by gauging the attitude of the students towards the use of a PC expressed in their behavior towards a PC as suggested by Selwyn (1997). It should be stressed that the concept "negative behavior" is used differently from behavior like, for instance, Internet addiction (Odaci, 2013), or personal use of e-mail at the office (Baturay \& Toker, 2015). The importance of these four variables in explaining attitudes toward ICT and the use of ICT has already been confirmed (e.g., Verhoeven et al., 2010; De Wit et al., 2012; Lai, Wang, \& Lei, 2012; Edgar, Johnson, \& Cox, 2012; Mac Callum \& Jeffrey, 2013; Mac Callum et al., 2014; Asil, Teo, \& Noyes, 2014), although they cannot explain the acceptance of all forms of new technologies (Verhoeven et al., 2010; De Wit et al., 2012).

In addition to these four TAM variables, we introduce a fifth into our model: "ICT science". This variable expresses the strength of the student's belief in the benefit of ICT in science. We presume that students are socialized with the idea that scientific research can progress faster by using ICT. University students, for whom scientific research is one of the key objectives of their training, will probably try harder to master the basic ICT skills, because they perceive these competences as being very helpful for scientific research. This hypothesis is supported by Spiezia's (2010) research among 15 year olds, in which a positive relationship was observed between the frequency of computer use and science scores.

To sum up our hypotheses, it is our purpose to build and test a model for the explanation of difference in self-reported ICT skill levels, based on socialization theory and on the TAM. In our model, we first check whether the socialization context contributes to a positive attitude to PC use. In particular, we examine the PC use of the student's family at home and at work, the attendance of the student in a special ICT course in secondary school, and also whether a more positive 
attitude can be discerned in male than in female students, in younger than in older students, and in students who started using a PC at a young age versus those who started at an older age. In a second step, we look into whether students assess their self-efficacy in ICT skills higher when they think that a PC is useful for their study or work, believe that they have control over a PC, are not anxious about or averse to computer use, or see the advantages of ICT for scientific research.

\section{Methods}

In order to explain proficiency in basic ICT skills, we constructed a structural equation model (SEM). This model was tested by using the results of an online questionnaire. All second and third year bachelor's STEM students at a large, research-intensive Belgian university were invited to answer the questionnaire. If they had not answered within two weeks, they received a second (and, if necessary, third) invitation. This method delivered 297 usable questionnaires $(41.36 \%$ of the 718 invited students). About $10 \%$ of the invited students started the questionnaire but dropped out before completing it, and two questionnaires had to be removed because most questions were left unanswered. The questionnaire focused on the self-perceived mastery of ICT skills and on the previously-mentioned explanatory variables. The questionnaire also included questions about the frequency of using a computer, ICT instruments, and ICT software. However, we do not discuss those results in this article. Official university statistics on key variables (gender, age, and faculty) were used to compare discrepancies between the population and the actually obtained sample. It was found that the nonresponse had led to slight deviations in these distributions. No special reasons for these small deviations were observed. Like many online questionnaires, this questionnaire could have to compete with other obligations of the students. We used iterative proportional fitting to calculate a corrective weighting variable that was subsequently used for descriptive purposes only. We opted for second and third year students in order to be certain that they would already have had some experience of ICT usage at the university and would have a better idea about what scientific research entails. The major group of these STEM students is male and the largest proportion of the students has parents who graduated in higher education. The average age is $19.42(\mathrm{SD}=0.70)($ see Table 1$)$.

Table 1. Demographic information of the students

\begin{tabular}{llrr}
\hline & & $\mathbf{N}$ & $\mathbf{\%}$ \\
\hline Gender & Male & 186 & 62.63 \\
Age & Female & 111 & 37.37 \\
& 18 & 24 & 8.08 \\
& 19 & 163 & 54.88 \\
& 20 & 91 & 30.64 \\
Education of parents & 17 & 5.72 \\
& 21 & 2 & 0.67 \\
& 22 & & \\
& Mother & 54 & 18.18 \\
& No higher education & 240 & 80.81 \\
& Higher education & 3 & 1.01 \\
& Do not know & & \\
& Father & 56 & 18.86 \\
& No higher education & 233 & 78.45 \\
& Higher education & 8 & 2.69 \\
\hline
\end{tabular}

The dependent variable in our structural equation model, ICT skill level, is a second-order latent variable that includes seven lower-order latent variables: PC maintenance skills, word processing 
skills, spreadsheet skills, database skills, presentation software skills, Internet browsing skills, and electronic communication skills. This is explained in greater detail in the following subsection. Each of the lower-order factors was measured with several survey questions. Responses were recorded on 5-point Likert-type scales.

The baseline SEM includes five latent variables and six observed variables to explain the ICT skill level. The latent variables were treated as intermediate variables, located between the observed variables and the dependent latent variable. This is depicted in Figure 1. The premise of this baseline model is that the dependent variable "ICT skills" is influenced by the five intermediate latent variables, which in turn are influenced by the observed variables, while none of the observed variables exert a direct effect on ICT skills. Naturally, the purpose of fitting a SEM is to evaluate (amongst other things) whether this assumption is tenable.

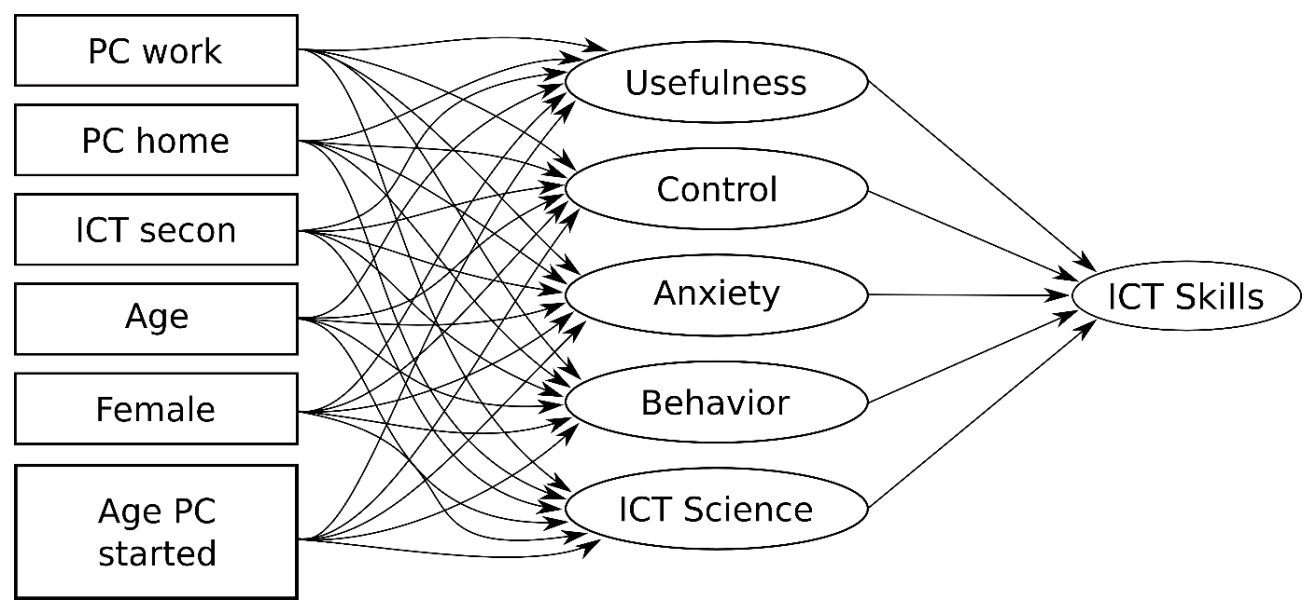

Figure 1. Baseline SEM

Four of the five intermediate latent variables are derived from the TAM, and are represented in Figure 1 as "usefulness", "control", "anxiety", and "behavior". The final latent variable - "ICT science" - reflects the degree to which students believe active scientists need ICT to perform a good job. This part of the model is explained in greater detail below.

All model fitting was performed using lavaan version 0.5-16 in R version 3.1.1 (Rosseel, 2012), on a 64-bit Windows 7 machine. Robust weighted least-square estimation methods were used. In contrast to the univariate, descriptive statistics we used earlier to describe our study object, we do not use iterative proportional fitting for the SEM but use age and gender as control variables in the model.

\section{Development of a Measurement Model for ICT Skills}

Since ICT skills became important in social life, many researchers have tried to construct instruments to measure these skills (Nair \& Das, 2011; Maneschijn et al., 2013). Some have defended an approach that would measure the real application of the ICT skills by the respondents (for instance, Madigan et al., 2007), but a larger proportion of researchers have opted to use the selfperception of ICT skills by the respondents (Nair \& Das, 2011; Maneschijn et al., 2013). Some others have preferred to combine the former approaches (Hohlfeld et al., 2013; Huggins, Ritzhaupt, \& Dawson, 2014). All these approaches have advantages and disadvantages. For our study, we chose to measure ICT skills using an instrument that relies on Likert-type scale answers, expressing the self-perception of the students. Introducing substantial diversification of the different competences, students were invited to express a nuanced picture of their ICT skills. Students were asked to reflect on their capacity to execute particular tasks for the maintenance of a 
PC, to work with a word processor, to work with a spreadsheet, and so forth. We postulate that presenting ICT skills in small, well delineated and easily recognizable acts yield more reliable answers. We opted for the basic ICT skills as detailed by the US Committee on Information Technology Literacy (1999) and the ECDL (2010), together with our own experience. In a pilot study, 123 Likert-type items were presented to 85 students from the same university. Factor analysis reduced this instrument to 49 items (see Table 2).

Table 2. Number of survey items and variable names of ICT skill domains

\begin{tabular}{lcc}
\hline ICT skill domain & Number of survey items & Variable names \\
\hline PC maintenance skills & 7 & V109-V115 \\
Word processing skills & 6 & V116-V121 \\
Spreadsheet skills & 14 & V122-V135 \\
Database skills & 6 & V136-V141 \\
Presentation software skills & 6 & V142-V147 \\
Internet browsing skills & 7 & V148-V154 \\
Electronic communication skills & 3 & V155-V157 \\
\hline
\end{tabular}

The intention was to construct a single latent variable, which would capture the skill level of each participant. Because the data was collected using an instrument that covers several sub domains, a second-order confirmatory factor analysis approach was adopted. In this approach, the observed variables are allowed to load on their respective domains (the first-order factors), while each of these domains are allowed to load on an overall ICT skill domain (the second-order factor). This theoretical model is shown in Figure 2. In this figure, not all of the observed variables are shown in order to save space. For each first-order factor - for example, "PC maintenance" - only the first and the last item in the survey instrument (e.g., V109 and V115) are depicted. A dashed line between the two survey items shown represents the omitted variables, and the dashed arrow represents the omitted arrows linking the factors to the observed variable.

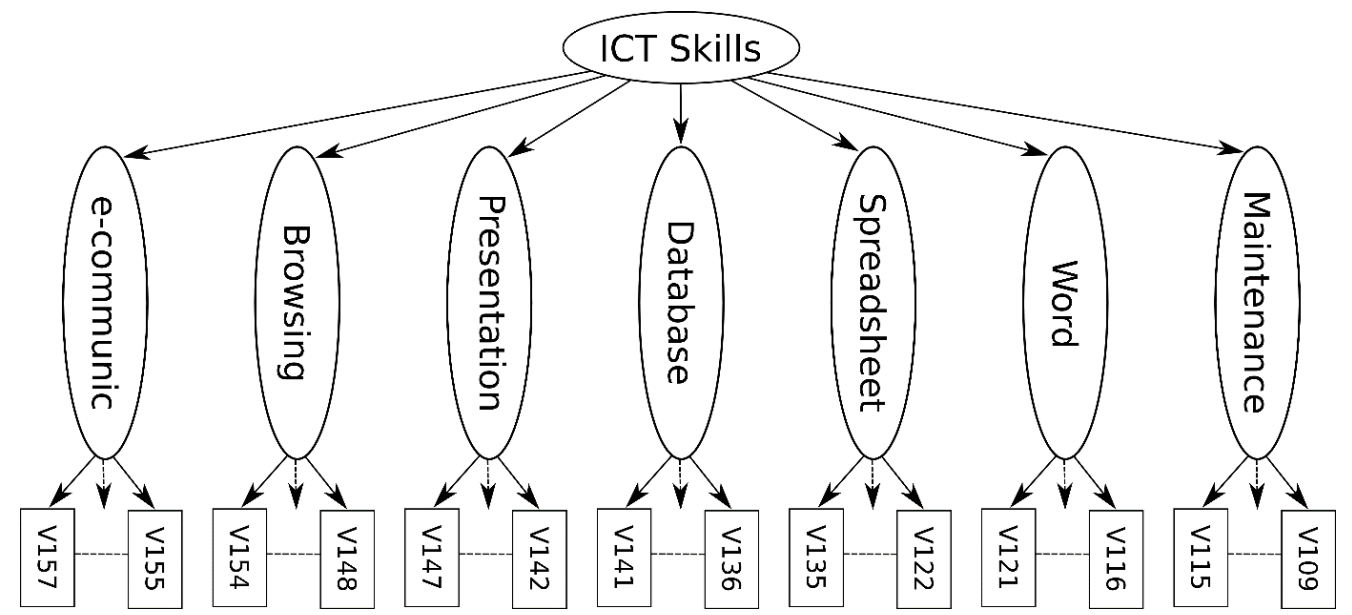

Figure 2. Baseline measurement model for ICT skills

In a first step, a CFA model was tested as shown in Figure 2, but without including the secondorder factor "ICT skills" (this was intentionally done to focus on the first level factors before imposing additional constraints on the model regarding the second level). This means the seven 
sub domains were allowed to covary freely (21 factor covariances were hence freely estimated). Global fit indices are acceptable (cf. Table 3, Model 1), with Confirmatory Factor Analysis (CFI) and Tucker Lewis Index (TLI) values exceeding 0.90 and Root Mean Square of Error Approximation (RMSEA) being below 0.05 . Based on the modification indices, it was apparent that local model fit could be improved. The relevant model modifications were mostly the inclusion of error covariances. The content of the survey items was closely evaluated before these modifications were made.

Table 3. Overview table: fit indices of the CFA models for ICT skills

\begin{tabular}{llll}
\hline Model & $\begin{array}{l}\text { Satorra-Bentler } \\
\chi^{2}(\mathbf{d f}), \mathbf{p}\end{array}$ & CFI/TLI & RMSEA (95\% CI) \\
\hline $\begin{array}{l}1-\text { baseline model without } \\
\text { higher order factor }\end{array}$ & $1522.409(1106), \mathrm{p}=.000$ & $.927 / .923$ & $.037(.033, .040)$ \\
$\begin{array}{l}2-\text { baseline model + 2 error } \\
\text { covariances }\end{array}$ & $1437.366(1104), \mathrm{p}=.000$ & $.942 / .938$ & $.033(.029, .037)$ \\
$\begin{array}{l}3-\text { model 2 + higher order } \\
\text { factor }\end{array}$ & $1521.258(1118), \mathrm{p}=.000$ & $.930 / .926$ & $.036(.032, .040)$ \\
$\begin{array}{l}\text { Model 4 - model 3 + error } \\
\text { covariance between "PC } \\
\text { maintenance" and "browsing" }\end{array}$ & $1470.354(1117), \mathrm{p}=.000$ & $.938 / .935$ & $.034(.030, .037)$ \\
\hline
\end{tabular}

A revised model was tested that included two error covariances. One error covariance was allowed between V149 and V150, which were not only located closely together in the questionnaire, but also covered by very similar topics: V149 (I can delete cookies from my computer using my web browser), and V150 (I can delete temporary Internet files from my computer using my web browser). Another error covariance was allowed between V130 and V131. Again, these items were not only presented in close proximity to each other, but were also very similar in content: V130 (I can create a graph in a spreadsheet) and V131 (I can change the graph type in a spreadsheet (e.g., change from a line graph to a bar graph)).

The revised model shows improved model fit (see Table 3, Model 2).

Model fitting then proceeded by including a second-order factor, "ICT skills", thereby substituting 7 factor loadings (of the first order factors onto the second order factor) for the 21 factor covariances in Models 1 and 2. Model fit deteriorated significantly between Model 2 and the higherorder factor model (Model 3 in Table 3). Therefore, model modifications were considered in order to improve model fit. A large modification index was associated with allowing a covariance between the residual variance of the latent variables "PC maintenance" and "Internet browsing". The content of these items are not similar in topic (e.g., "I can force shut down of a nonresponsive program" from the "PC maintenance skills" domain, and "I can delete cookies from my computer using my web browser" from the "Internet browsing" domain). However, they are similar in that they represent somewhat more advanced computer skills that are not possessed by the average computer user. Based on this reasoning, a modified model was fitted which included the error covariance between "PC maintenance" and "Internet browsing".

Although the fit of Model 4 was still lower than that of Model $2\left(\chi^{2}\right.$ difference of 33.165 for 13 degrees of freedom, $p=.002$ ), this model was accepted as the final measurement model for ICT skills, based on global fit indices, its parsimonious nature, and the absence of any exceptionally large modification indices. 
In order to explain why science students attain a certain level of ICT skills we have referred in the section 'Theory' to a theory explaining why actors might show a certain level of openness for new technology (TAM), and a socialization theory where the socializing power of family and school can stimulate the acceptance of new technology, in this case mastering some ICT skills working with the PC. As far as TAM is concerned we describe the instruments for measuring the anxiety of students for a PC and the way they behave towards a PC, their assessment about the usefulness of a computer, and their assessment about their ease of use of or control over a PC. We also describe the development of a scale that gauges the attitude of the student towards the necessity of computers for science. These are the intermediate latent variables. These will be followed by a short description of the six observed variables that have a special meaning for the socialization process: (1) the use of a PC by family members at work; (2) the use of a PC by family members at home; (3) did students get some formal course about ICT in secondary school; (4) the age of the students: (5) the gender differences; and (6) the age at first PC experience.

\section{Development of a Measurement Model for the TAM Variables}

The survey instrument contains 17 items designed by Selwyn (1997) to measure four TAM variables: usefulness of computers, perceived ease of use or control of computers, anxiety about computers, and behavior expressing a negative attitude toward a computer (see Table 4). Note that the items representing these variables are not focused on the different aspects of the basic ICT skills but on the use of a personal computer for work, study or leisure. Personal computers have a wider function than, for instance, using a word processing program or a spreadsheet, but they still are important instruments to apply these ICT skills. It could be said that the PC is the platform through which the ICT skills can be manifested. A positive attitude towards the PC might have its effect on the application of basic ICT skills. Many ICT skills can nowadays also be applied on a tablet or a smart phone, but for most students the personal computer is still the main instrument on which these basic ICT skills are used (see section 'Some Characteristics of the Students').

Table 4. Number of survey items and the corresponding basic variable names of the TAM variables

\begin{tabular}{lcl}
\hline TAM variables & $\begin{array}{l}\text { Number of } \\
\text { survey items }\end{array}$ & Basic variable names \\
\hline Usefulness of computers & 5 & V160, V162-V165 \\
Control of computers & 4 & V159, V169, V170, V174 \\
$\begin{array}{l}\text { Anxiety for computers } \\
\begin{array}{l}\text { Behavior expressing a negative attitude } \\
\text { towards PC }\end{array}\end{array}$ & 5 & $\mathrm{~V} 158, \mathrm{~V} 161, \mathrm{~V} 166, \mathrm{~V} 167, \mathrm{~V} 172$ \\
\hline
\end{tabular}

Figure 3 portrays the theoretically assumed structure in the data, which was tested as the starting or "baseline" model. As can be seen in Table 5, this model did not fit the data well. The CFI and TLI values are below 0.90 and the RMSEA value is above 0.05 . Inspection of the parameter estimates reveals that the latent variables "behavior" and "anxiety" are almost perfectly correlated ( $\mathrm{r}$ $=0.976$ ). This indicates that in this population of science students, these two concepts are not distinct. Because of this very large correlation, we decided to develop a revised model, in which the factors "anxiety" and "behavior" are combined into a single factor. 


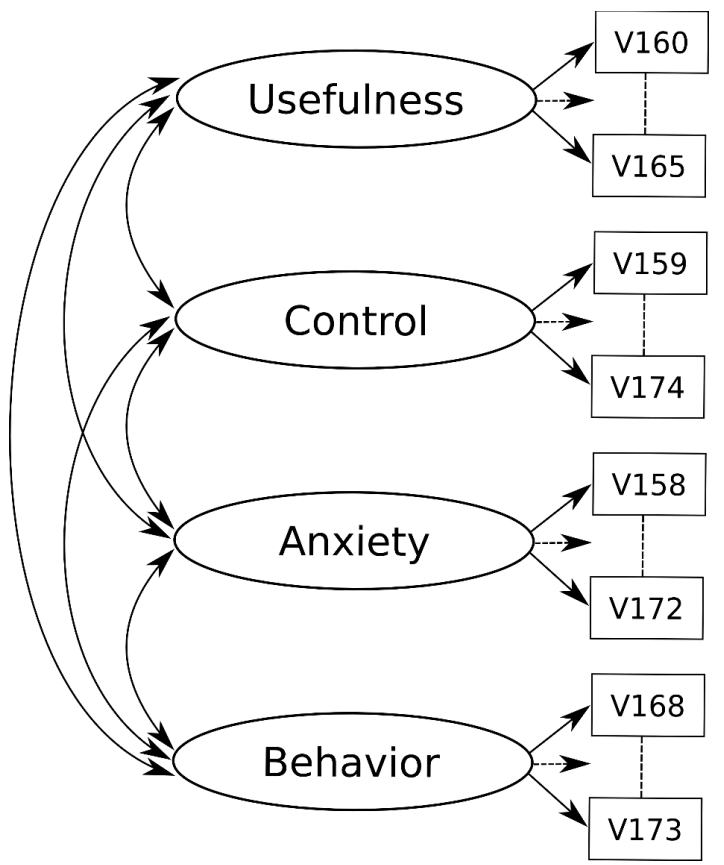

Figure 3. Baseline measurement model for the TAM variables

The revised model (Model 2, 3 factor model in Table 5) had a somewhat worse fit than Model 1, but a $\chi^{2}$ difference test revealed the difference to be only borderline significant $(\mathrm{p}=.076)$. We therefore chose to continue developing Model 2, mostly because it made no substantive sense to keep "behavior" and "anxiety" separate given their near perfect correlation $(\mathrm{r}=0.976)$. Modification indices suggested a cross-loading for item V169: instead of only loading on "control", it should also load on "anxiety/behavior". In fact, the item wording is: "I am not in complete control when I use a computer". While the "control" aspect is certainly present in this item, it is conceivable that this item also carries a notion of anxiety. Model 3 therefore includes this cross-loading. The effect of including this cross-loading was that model fit improved (see Table 5), but also that the mentioned item V169 no longer loaded significantly on the "control" factor (standardized factor loading $=-.110, \mathrm{p}=.125$ ).

Table 5. Overview table: Fit indices of the CFA models for TAM

\begin{tabular}{llll}
\hline Model & Satorra-Bentler $\chi^{\mathbf{2}}(\mathbf{d f}), \mathbf{p}$ & CFI/TLI & RMSEA (95\% CI) \\
\hline $\begin{array}{l}\text { 1 - baseline model as shown } \\
\text { in Figure 3 }\end{array}$ & $220.405(113), \mathrm{p}=.000$ & $.862 / .833$ & $.057(.048, .067)$ \\
2-3 factor model & $229.030(116), \mathrm{p}=.000$ & $.857 / .832$ & $.058(.048, .067)$ \\
3- Model 2 + cross loading & $200.180(115), \mathrm{p}=.000$ & $.892 / .873$ & $.050(.040, .060)$ \\
V169 & & & \\
$\begin{array}{l}\text { 4- Model 3 + cross loading } \\
\text { V172 }\end{array}$ & $177.587(114), \mathrm{p}=.000$ & $.920 / .904$ & $.044(.032, .054)$ \\
5- Model 4 + cross loading & $160.293(113), \mathrm{p}=.000$ & $.940 / .928$ & $.038(.025, .049)$ \\
V166 & & & \\
\hline
\end{tabular}


Modification indices then suggested a cross-loading for item V172, which reads: "I feel comfortable when using a computer". This item was initially intended to load on the "anxiety" factor (or the "anxiety/behavior" factor in the revised model), but the modification index suggested it should also be allowed to load on the "control" factor. Model 4 includes this cross-loading and shows an improved model fit (see Table 5). Nevertheless, local fit assessment led to the finding that the model might have to include a third cross-loading, this time V166 on "control". This item reads: "Using a computer does not scare me". This item was initially expected to load on "anxiety", but similar to the other two cross-loadings, it could be argued that this control item also carries a connotation of (absence of) anxiety. Model 5 was run with this cross-loading implemented and shows a good model fit (see Table 5).

Based on the analysis of the TAM variables, two main conclusions are worth mentioning. The first, of course, is that the "behavior" and "anxiety" factors cannot be distinguished in this sample of science students. The second is that items for the "control" and the "anxiety/behavior" factor easily cross-load, again indicating that these factors might be closely related (although the correlation in the final model between these two factors is a moderate -.382).

\section{Development of a Measurement Model for ICT science}

Eight items were used to measure students' perceptions regarding the necessity of ICT for scientists when conducting their work and a single-factor CFA model was run on these items. Model fit was acceptable according to the CFI and TLI criteria, but not according to the RMSEA, as can be seen in Table 6 . The modification indices suggest the addition of an error covariance between V204 and V206. These items are worded as follows: V204: "A scientific researcher should be good at working with databases", and V206: "A scientific researcher should be good at working with databases on the Internet". Clearly, both items have "databases" as a common theme, which explains the error covariance. Model 2 includes this error covariance. The model fit is very good, judged by very high CFI and TLI, an RMSEA of zero and a non-significant $\chi^{2}$ value.

Table 6. Overview table: Fit indices of the CFA models for ICT science

\begin{tabular}{|c|c|c|c|}
\hline Model & $\begin{array}{l}\text { Satorra-Bentler } \\
\chi^{2}(\mathrm{df}), \mathbf{p}\end{array}$ & CFI/TLI & RMSEA $(95 \%$ CI $)$ \\
\hline 1 - Baseline model & $60.495(27), p=.000$ & $.919 / .892$ & $.066(.048, .085)$ \\
\hline $\begin{array}{l}2-\text { Model } 1+\text { error covari- } \\
\text { ance between V204 and } \\
\text { V206 }\end{array}$ & $23.371(26), p=.612$ & $1 / 1$ & $.000(.000, .036)$ \\
\hline
\end{tabular}

\section{Fitting an Overall CFA Model}

Before moving to fitting a structural model, the three measurement models described above (ICT skills, TAM, and ICT science) were evaluated together in a single model. It should be noted that this overall measurement model includes the three final measurement models as described above (i.e., including the modifications as discussed). This model shows an acceptable global fit (Satorra-Bentler $\chi^{2}=3419.045, \mathrm{df}=2676, \mathrm{p}=.000, \mathrm{CFI}=.903, \mathrm{TLI}=.900, \mathrm{RMSEA}=.032$, 95\% CI: .029, .035). Local fit was assessed with modification indices. Based on a review of the modification indices, no model modifications were deemed necessary. Table 7 shows the five Likert-type scales, their Cronbach's $\alpha$, and some examples of the items. 
Table 7. Likert-type scales and item examples

\begin{tabular}{|c|c|}
\hline Likert-type scales & Item examples \\
\hline \multicolumn{2}{|l|}{ ICT skills (49 items) (Cronbach's $\alpha=.95$ ) } \\
\hline Maintenance & - I can adjust the resolution of my monitor. \\
\hline Word processor & - I can create a table to display data. \\
\hline Digital spreadsheets & $\begin{array}{l}\text { - In a digital spreadsheet I can format the cells } \\
\text { so that numbers with a specific number of dec- } \\
\text { imal digits are displayed. }\end{array}$ \\
\hline Database & $\begin{array}{l}\text { - I can create a new, simple database and put } \\
\text { data in it. }\end{array}$ \\
\hline Presentation program & $\begin{array}{l}\text { - In a presentation program I can enter data to } \\
\text { create a chart. }\end{array}$ \\
\hline Browser & $\begin{array}{l}\text { - With a Web browser I can delete the Web } \\
\text { browser history. }\end{array}$ \\
\hline Communication & $\begin{array}{l}\text { - I can create filters to send emails automatically } \\
\text { to specific folders (e.g., study, football, etc.). }\end{array}$ \\
\hline $\begin{array}{l}\text { Anxiety/behavior (9 items) (Cronbach's } \alpha \\
=.84)\end{array}$ & - Computers make me feel uncomfortable. \\
\hline Useful (5 items) (Cronbach's $\alpha=.72)$ & $\begin{array}{l}\text { - Computers can enhance the presentation of my } \\
\text { work to a degree which justifies the extra ef- } \\
\text { fort. }\end{array}$ \\
\hline Control (6 items) (Cronbach's $\alpha=.73$ ) & $\begin{array}{l}\text { - I do not need someone to tell me the best way } \\
\text { to use a computer. }\end{array}$ \\
\hline ICT science (9 items) (Cronbach's $\alpha=.83$ ) & $\begin{array}{l}\text { - Today, a scientific researcher cannot work } \\
\text { properly without a computer. }\end{array}$ \\
\hline
\end{tabular}

\section{Observed Explanatory Variables}

The six observed explanatory variables refer to the position a student has in social situations that might be beneficial for the development of ICT skills. On the basis of the literature review above, these variables are defined as follows.

"PC work" concerns the use of a computer at work by the father, mother, and siblings (score range $=0$ to 3 ). "PC home" indicates whether the father, mother, and siblings use a computer at home (score range $=0$ to 3 ) (Vekiri, 2010a). "ICT secon" records if students took an ICT course in secondary school (score 1) or not (score 0) (De Wit et al., 2012). "Age" refers to the age of the student (range $=18-22)$. "Age at first PC experience" refers to the age at which a student started to use a PC (Aslanidou \& Menexes, 2008; Kubiatko \& Vlckova, 2010). Gender is expressed by 1 for female and 0 for male students (dummy variable) (Volman \& van Eck, 2001; Losh, 2004; Becker, 2006; Madigan et al., 2007; Kubiatko, 2010; Zhao et al., 2010; van Deursen \& van Dijk, 2015). 


\section{Results}

\section{Some Characteristics of the Students}

Most of the students (83\%) were living in rooms in the university town, but a small group (17\%) lived at home during the academic year. All the students had the use of a computer $(92 \%$ were laptops) at their room and/or at home, and all students had access to the Internet in their rooms at university and/or at home. Moreover, in many places at the university, computers were freely available for the students, so we can state that access to computers and the Internet was universal.

Many students grew up in families where parents or siblings used a computer at home (score $=$ 2.75 out of $3, \mathrm{SD}=0.49)$. The group where parents or siblings used a computer at work is relatively small (score $=1.83$ out of $3, \mathrm{SD}=0.77$ ), and interestingly, among the parents of these students the gender digital divide was still present at work ( $86 \%$ of the fathers used a computer at work, and only $64 \%$ of the mothers did). At home, the divide was nonexistent: $91 \%$ of both the fathers and the mothers used a computer at home. A computer at home seems to be accepted by most families as a useful instrument, thus creating a laboratory in which children can often freely use a computer and learn how to work with it. Students indicated that they learned most about computer use from their own experience ( score $=3.56$ out of $4, \mathrm{SD}=0.59$ ), then from their peers ( score $=2.65$ out of $4, \mathrm{SD}=0.7$ ), their teachers ( score $=1.99$ out $4, \mathrm{SD}=0.45$ ), or from family ( score $=1.75$ out of $4, \mathrm{SD}=0.45)$. They received the most support from their peers (score $=3.22$ out of $4, \mathrm{SD}=0.74)$, more than from their parents or siblings ( or their teachers (score $=1.67$ out of $4, \mathrm{SD}=0.68$ ).

At the university, computers and the Internet are part of daily life for students. In carrying out their studies, $71 \%$ of the STEM students in our sample used their computer daily and $21 \%$ more than four times a week. For use of the Internet, these figures are $70 \%$ and $21 \%$ respectively. Moreover, $89 \%$ used a computer daily for purposes other than studying, and $8 \%$ did this four to five times a week. One could almost claim that computers and the Internet are part of daily life of STEM students as much as food or air.

In view of these figures, it is no surprise that these students score very high for ICT skills (4.12 out of $5, \mathrm{SD}=0.56)$, and score very low on the anxiety/behavior scale $(1.62$ out of $5, \mathrm{SD}=0.63)$. They consider themselves to have a relatively high command over computers (score 3.94 out of 5, $\mathrm{SD}=0.7$ ), and they believe that computers are useful for work (score $=3.9$ out of $5, \mathrm{SD}=0.7$ ). They further have a positive attitude concerning the necessity of ICT for carrying out scientific research (score $=3.91$ out of $5, \mathrm{SD}=0.54$ ), but they also indicate that not all steps of scientific research have to be done with the help of a computer.

\section{Fitting a SEM to Explain the ICT Skill Level}

Our SEM model was constructed based on the overall CFA model. "ICT skills" was assumed to be influenced by the TAM variables and "ICT science", while these variables were in turn expected to be influenced by the observed variables. The model is shown in Figure 4. It should be noted that the latent variables "usefulness", "control", "anxiety/behavior", and "ICT science" influence observed variables as explained in the sections on the measurement models. However, these are not shown in the graph to keep it legible. Similarly, ICT skills in fact influences seven sub factors (PC maintenance, word processing, spreadsheet, database, presentation software, Internet browsing, and e-communication), which in turn influence 49 observed variables. All of this is omitted from the graph in order to keep it manageable. However, the model fitted does include all these parts. 


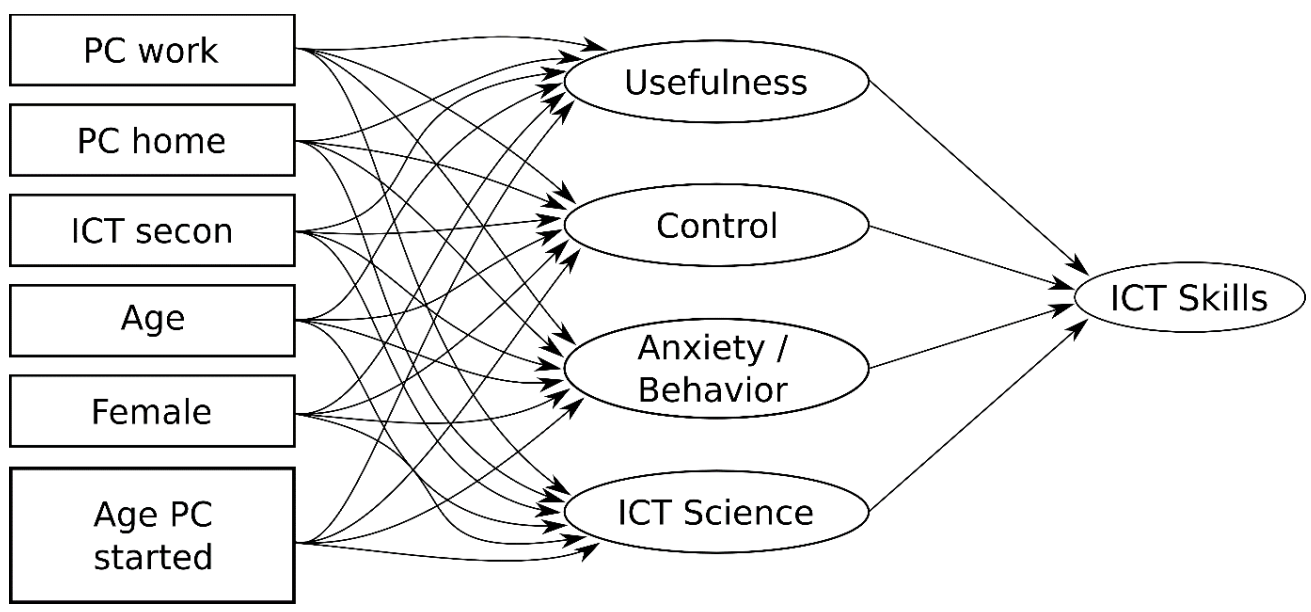

Figure 4. Structural model 1

The fit of this model was below conventional thresholds. Satorra-Bentler $\chi^{2}$ is 4082.544 for 3108 degrees of freedom $(\mathrm{p}=.000)$, CFI is .881 , and TLI is .877 . However, RMSEA is below the traditional .05 cut-off value $(.034$ with a $95 \%$ CI of $.032, .037)$. Nonetheless, the model included many non-significant paths from the observed variables on the intermediate latent variables. Setting these paths to zero simplifies the model and potentially improves model fit indices which take into account model parsimony. In addition, there were no paths allowed from the observed variables to the ICT skills variable. Adding any significant paths (set to 0 in model 1) would also improve model fit.

A second model first included all possible paths from the observed variables on ICT skills. Model fit was not appreciably different from that of Model 1: Satorra-Bentler $\chi^{2}$ is 4075.923 for 3102 degrees of freedom $(\mathrm{p}=.000)$, CFI is .881 , TLI is .877 , and RMSEA is .034 with a $95 \%$ CI of $.032, .037$. The reason for the similar fit is probably that none of the direct paths from the six observed variables on ICT skills reached statistical significance.

Based on Model 2, non-significant paths were left out of the model in a stepwise fashion. First, all paths with a p-value greater than .40 were omitted. In a second step, paths with a p-value greater than .20 were left out, and finally paths with a p-value of greater than .10 were left out.

The final model has an acceptable fit: Satorra-Bentler $\chi^{2}$ is 3721.640 for 2826 degrees of freedom $(\mathrm{p}=.000), \mathrm{CFI}$ is .887 , TLI is .883 , and RMSEA is .035 with a $95 \%$ CI of $.032, .037$. The final model is shown in Figure 5. Only the structural parameters are displayed. More detailed information can be found in the Appendix. Note that not all 297 respondents answered every single question. The model removed any incomplete sets of answers (list-wise deletion), leading to a usable sample size of $\mathrm{N}=266$. The $\mathrm{R}^{2}$ value of the dependent latent variable - ICT skills amounts to .81. This high value seems to be mainly driven by the very large effect of "control" on this variable (standardized effect parameter value: .846). This suggests that the skill level of the seven ICT domains, measured by 49 variables, can be very closely approximated by just four variables that measure "control". It suggests that the four "control" variables represent a highlevel summary of what is measured with the 49 detailed questions on specific ICT skills.

Another striking result is that each of the intermediate variables is influenced by the age at which the students started using a PC. Students who started to use a PC at an older age perceive computers as less useful, perceive themselves as being less in control of using a computer, are more anxious about using PCs, and think less that a scientific researcher needs to be competent with ICT in order to do a good job. 
The total effect of age at first experience with a computer on ICT skills, controlling for PC use at work, PC use at home, ICT course in secondary school, age, and gender, amounts to $-0.29(-0.244$ $* 0.208+[-0.353 * 0.846]+[0.184 *-0.172]+[-0.182 * 0.171]+0.123)$. This means that for each standard deviation delay in starting to use a PC, 0.29 standard deviations are lost on the ICT Skills factor. When controlling for the mediating factors "Usefulness", "Control", "Anxiety/Behavior" and "ICT Science", age at first PC use exerts a modest positive effect on ICT Skills $(+0.123)$. This seemingly contradictory finding needs to be interpreted cautiously, as it means that individuals who started using a PC at a later age are expected to have slightly higher ICT skills, but only on the condition that they have equal scores on the mediating variables "Usefulness", "Control", "Anxiety/Behavior" and "ICT Science".

Only one other variable, gender, influences an intermediate latent variable. Females feel less in control of using a PC than males. Because this control variable exerts such a large influence on ICT skills, it also implies that females score lower on the ICT skills variable than males.

Taken together, these results suggest that within a sample of science students, starting to use the computer at an early age is an important factor in building confidence and ICT skills.

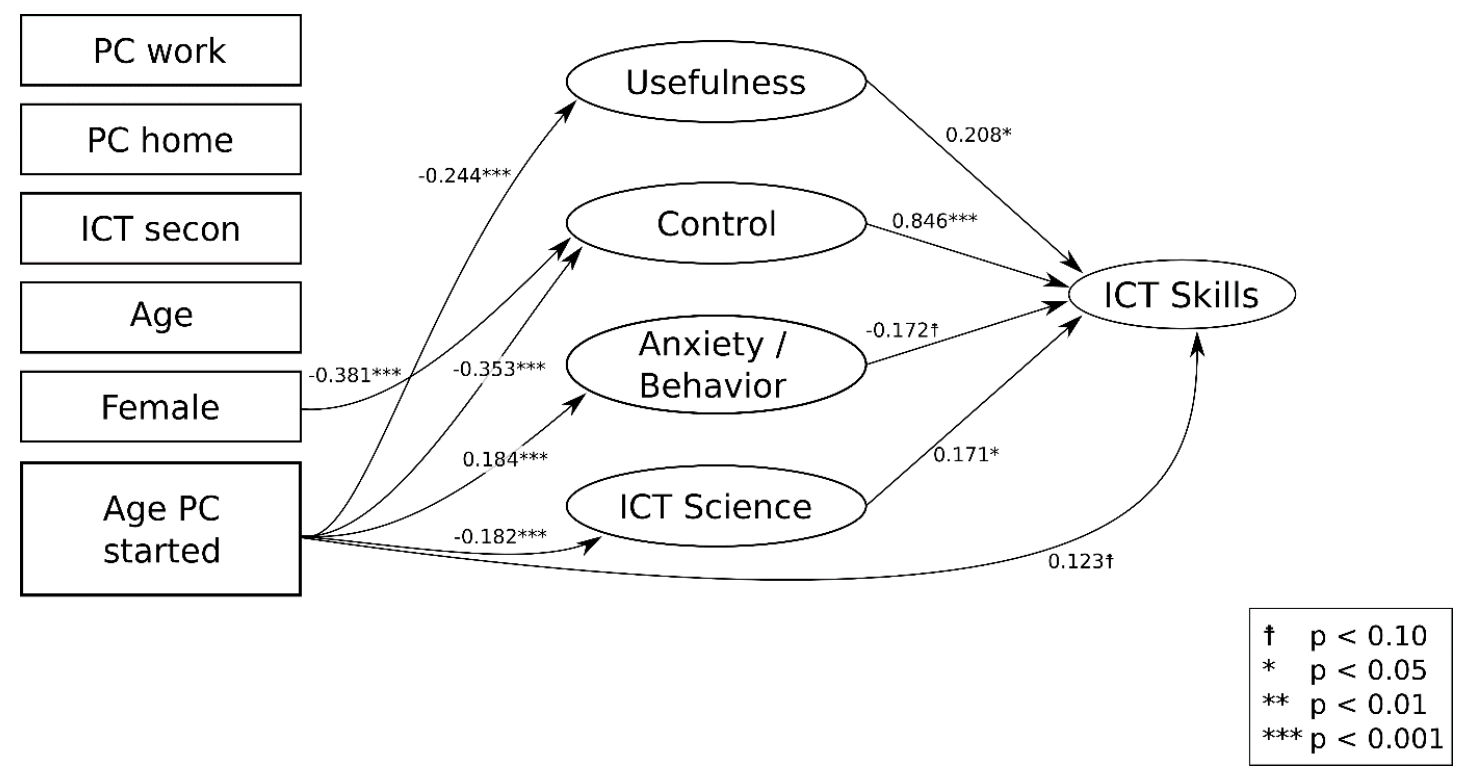

Figure 5. Final SEM model: Completely standardized effect parameters shown $(\mathrm{N}=\mathbf{2 6 6})$

\section{Discussion}

Our purpose was to explore the self-assessment of basic ICT skills by science bachelor's students. For this purpose, we refer to the positions of students in a socialization process in relation to the use of PCs, and to the possible influence of the educational level of the parents, and the age and gender of the student. We also examine whether these factors contribute to the explanation of the attitudes of the students to the acceptance of ICT and their opinion about the link between scientific research and ICT. Using the socialization, technology acceptance, and science factors, we constructed a structural equation model (SEM).

To measure basic ICT skills, we chose an online instrument composed of a large number of items describing what a person thinks they are capable of doing, starting from the idea that a detailed measurement of specific ICT skills would enhance the probability of respondents providing a more reliable picture of their ICT skills, because they would be able to relate the detailed skills to their actual experience. At the same time, this means that we did not invite students to actually 
apply some basic ICT techniques. According to some, this approach would avoid the danger of a biased report delivered by the interviewee (see Madigan et al., 2007; Hohlfeld et al., 2013), as using respondents' judgments about a form of self-efficacy is vulnerable (Hsu, Wang, \& Runco, 2013). However, such an approach is also not void of problems. Even if it was possible to construct an actual test for all forms of ICT skills, it might still be a problem to obtain the cooperation of the respondents to sit for long enough to carry out the test. Therefore, the instrument we developed can be said to be both feasible and useful to reliably give a picture of the ICT skills of students.

The impact of socialization is limited in this research to the socialization position of the students, without taking into account the complexity of the socialization process. For example, we measured whether students grew up in families where parents and siblings used a PC at home or at work, but we did not include how often this PC was used, how it was appreciated, and whether students were stimulated by their parents to use a PC. Further, we have information about the gender of the students, but we do not have information regarding whether the parents educated their children traditionally or in a gender-neutral manner. The focus on the socialization position might explain why our research shows that there is no influence from these family characteristics when looking at second and third year students, whereas other research has shown an influence on young students (Vekiri \& Chronaki, 2008; Vekiri, 2010a). To be able to assess the impact of the socialization process, in other words to answer the question of whether ICT socialization occurs differently in families with PC-orientated parents than in other families, it would be fruitful to carry out qualitative research. Similarly, qualitative approaches would be needed in order to detect possible differences in the ICT socialization of girls and boys, and of children of parents with higher or lower educational backgrounds. It must be noted in this respect that we did not include the educational background of the parents in the SEM, because there was almost no correlation between the proficiency in ICT skills of the students and the education level of the parents $(\mathrm{r}=-.027 ; \mathrm{p}=.651)$.

Our SEM also shows that the impact of ICT classes in secondary school is not apparent in the ICT skills of the students. However, this does not imply that these ICT classes are ineffective. They have most probably been useful for many students, although our survey data shows that teachers have not been a great support with regard to ICT. It is likely that students who finish secondary school and start to study at university have already gathered a high level of ICT experience, to such an extent that the difference between those who did or did not take an ICT course in secondary school is no longer traceable. In-depth qualitative research could offer an answer to this question.

It is interesting to note that both the socialization position of the students and their having attended ICT classes in secondary school do not seem to have a significant impact on their perceived ICT skills, whereas the age they started using a PC clearly does have an effect. This seems to indicate that the role of socialization in the family and in school has worn off by the time science students are in their last bachelor's years, whereas the impact of what they have learned by themselves remains stronger. This correlates with the finding that students see themselves as principal source of their knowledge and skills with regard to using computers. It would appear in this sense that it is important to allow children to experiment with the use of computers and software on their own, as this is the most important way in which they acquire ICT competences.

In this article, we study proficiency in ICT skills as a generic concept. In this way it was shown that the proficiency of science students in general terms is high. Nevertheless, it is obvious that the high average score on self-perceived skills somewhat conceals that these students attain different levels of proficiency with regard to different basic ICT skills (PC maintenance, word processing, spreadsheets, and so forth). In future research, it would therefore make sense, first, to test the SEM with other groups of students than science students and, second, to ascertain whether the 
SEM used in the current article to explore basic ICT skills in general would yield similar results for all groups of basic ICT skills separately.

\section{Conclusion}

In this article, we have detailed the construction and testing of a structural equation model that allows exploring the differences in the self-reported level of the basic ICT skills of STEM bachelor's students. Both the construction of a SEM in which the proficiency in basic ICT skills of students is explored, and the use of a more elaborate instrument to measure the ICT skills level, focused on science students, are novel ways to unravel the ICT proficiency of students. ICT skills were measured using an instrument that asks students to assess in detail whether they can perform a particular task using a computer or the Internet. This measurement confirms the expectation that science students would score high on this scale ( score $=4.12$ out of 5$)$. The explanation for this high level of (self-perceived) ICT skills has been sought in the socialization conditions of the students, their attitude toward computers (which is also influenced by the socialization conditions) and their opinion about the usefulness of ICT for scientific research.

Overall, our model explains a large part of the variation in proficiency in ICT skills of bachelor's science students $\left(\mathrm{R}^{2}=.81\right)$. Most explanatory power comes from the TAM variables (i.e., the students' acceptance of technology) and the variable "ICT science" (i.e., the students' belief that scientists need ICT to do their job properly). The model also shows that the different socialization conditions do not explain much of the ICT skills of this sample of students.

Although it is obvious that the attitude of parents and siblings toward computers will have an influence on children, we observe that at the age of 18-22 years, the possible difference in ICT socialization within the family is no longer evident in the ICT scores of the students. This does perhaps not come as a surprise, as there are ample opportunities for students to catch up on ICT skills outside their home. Similarly, we find no impact of having followed an ICT course in secondary school in comparison with not having attended such a course. In addition, no specific consequences or basic ICT skills are observed between the different age cohorts, albeit that the age range 18-22 is rather narrow and that perhaps there would have been differences if students had been 30 or above, because computers were not yet ubiquitous in the 1990s.

The often-quoted digital divide relating to gender, which we also found among students in 2004 and 2005 (see Verhoeven et al., 2010), seems to have disappeared among bachelor's science students (see also Hohlfeld et al., 2013; Bovée et al., 2007; Wang et al., 2009; De Wit et al., 2012). Our current research indicates that, at least among science students, the observation of a gender divide has to be refuted. Women students do still believe they have less control over computers than male students do, however, they do not show more anxiety about working with computers and consider them to be as useful as the male students do. Moreover, men and women have the same opinion about the necessity of ICT for scientific research. The strongest impact on the attitude toward computers and the self-perception of ICT skills relates to the age at first experience of a computer. The younger the students were when they first had PC experience, the higher they score on usefulness and control of computers, and the more they consider ICT necessary for scientific research. The other way round, anxiety about using a computer is higher among students who had their first PC experience later in life. These observations find some support made by other researchers although they do not refer to higher education or basic ICT skills. For instance, Aslanidou \& Menexes (2008) observed that younger students in secondary education use the Internet more than older students, Kubiatko \& Vlckova (2010) found that in secondary schools pupils who were well connected with ICT scored also higher in science knowledge tests, and van Deursen \& van Dijk (2015) observed in a longitudinal project that younger people still have more Internet skills than the older generations. 
The self-perceived proficiency in ICT skills is higher for science students who see computers as useful and necessary for scientific research. From this we might infer that promoting the usefulness of computers and the need of ICT for science could enhance science students' proficiency in ICT skills. Having the feeling of having control over a computer has the strongest impact on reported proficiency in ICT skills. This confirms observations made in our former research projects (Verhoeven et al., 2010; De Wit et al., 2012), and in other research as well, although the latter does not always endorse having control over the technology as the most important factor. For instance, both Davis (1989) and Venkatesh et al. (2003) found that perceived control was an important factor to explain the acceptance of information technology, but not more than other factors such as perceived usefulness. Contrary to these observations, Lai et al. (2012) found only a weak influence from the perceived usefulness of a computer and almost no influence from "computer self-efficacy" (perceived control) on students' learning technology adoption. Interestingly, with regard to the intention to adopt mobile learning, Mac Callum and Jeffrey (2013) and Mac Callum et al. (2014) found a strong influence of the perceived usefulness and the perceived ease of use of mobile learning. Looking back at our observations it is reasonable to contend that the development of a feeling of control over computers can contribute to improving proficiency in ICT skills, although the observations by other researchers incite for some prudence. The same is true for the reduction of anxiety regarding computers. Although one would not readily expect anxiety for computers in a STEM student, our research shows that it still is an issue for (some) students. Here again, it is important to note that although socialization conditions do not account for differences in the proficiency in basic ICT skills, we did find that the younger science students have experienced a computer the more positive they appreciate the use of a computer. Therefore, it would seem important to give computers and the Internet a normal place in daily life of children from an early age.

Taking into account the design and the results of this research, we see at least two avenues for further research. First, it would be interesting to apply our instrument and our structural equation model to other groups of students (e.g., younger students, non-science students), in order to assess its robustness. Second, future qualitative research could delve into the diversity of the socialization process in the families of students. All kinds of ICT instruments (not only computers in the strict sense but also tablet computers, smart phones, smart TVs) are becoming more and more present in many families, but the way these instruments are used in relation to the children and in the hands of the children might be very diverse, involving the use of particular hardware as well as the exposure to or the usage of specific software. Unearthing the educational patterns in relation to the use of different ICT instruments might bring to light an interestingly varied picture of how these instruments are used within the family and the effects this has on the mastery of basic ICT skills later in life.

\section{References}

Al-Rsa'i, M. S. (2013). Promoting scientific literacy by using ICT in science teaching. International Education Studies, 6(9), 175-186.

Asil, M., Teo, T., \& Noyes, J. (2014). Validation and measurement invariance of the computer attitude measure for young students (CAMYS). Journal of Educational Computing Research, 51(1), 49-69.

Aslanidou, S., \& Menexes, G. (2008). Youth and the Internet: Uses and practices in the home. Computers \& Education, 51(3), 1375-1391.

Bandura, A. (1982). Self-efficacy mechanism in human agency. American Psychologist, 37(2), 122-147.

Baturay, M. H., \& Toker, S. (2015). An investigation of the impact of demographics on cyberloafing from an educational setting angle. Computers in Human Behavior, 50, 358-366. 
Becker, J. D. (2006). Digital equity in education: A multilevel examination of differences in and relationships between computer access, computer use, and state-level technology policies. Education Policies Archives Analysis, 15(3). Retrieved from http://epaa.asu.edu/epaa/v15n3/

Berger, P. L., \& Luckmann, T. (1966). The social construction of reality. A treatise in the sociology of knowledge. Harmondsworth: Penguin Books.

Bøe, M. V., \& Henriksen, E. K. (2013). Love it or leave it: Norwegian students' motivations and expectations for postcompulsory physics. Science Education, 97(4), 550-573.

Bøe, M. V., Henriksen, E. K., Lyons, T., \& Schreiner, C. (2011). Participation in science and technology: young people's achievement-related choices in late-modern societies. Studies in Science Education, 47(1), 37-72.

Bovée, C., Voogt, J., \& Meelissen, M. (2007). Computer attitudes of primary and secondary students in South Africa. Computers in Human Behavior, 23(4), 1762-1776.

Ḉalik, M., Özsevgeç, T., Ebenezer, J., Artun, H., \& Küçük, Z. (2014). Effects of 'Environmental Chemistry' elective course via technology-embedded scientific inquiry model on some variables. Journal of Science Education and Technology, 23(3), 412-430.

Celik, V., \& Yesilyurt, E. (2013). Attitudes to technology, perceived computer self-efficacy and computer anxiety as predictors of computer supported education. Computers \& Education, 60(1), 148-158.

Chen, S., Chang, W. H., Lai, C. H., \& Tsai, C. Y. (2014). A comparison of students' approaches to inquiry, conceptual learning, and attitudes in simulation-based and microcomputer-based laboratories. Science Education, 98(5), 905-935.

Cheryan, S., \& Plaut, V. C. (2010). Explaining underrepresentation: a theory of precluded interest. Sex Roles, 63, 475-488.

Chowdhury, S., Gibb, F., \& Landoni, M. (2011). Uncertainty in information seeking and retrieval: A study in an academic environment. Information Processing and Management, 47(2), 157-175.

Committee on Information Technology Literacy. (1999). Being fluent with information technology. Washington DC: National Academy Press.

Davis, F. D. (1989). Perceived usefulness, perceived ease of use, and user acceptance of information technology. MIS Quarterly, 13(3), 319-340.

De Wit, K., Heerwegh, D., \& Verhoeven, J. C. (2012). Changes in the basic ICT skills of freshmen between 2005 and 2009: Who's catching up and who's still behind? Education and Information Technologies, 17(2), 205-231.

Domene, J. F., Socholotiuk, K. D., \& Woitowicz, L. A. (2011). Academic motivation in post-secondary students: Effects of career outcome expectations and type of aspiration. Canadian Journal of Education, 34(1), 99-127.

Donnelly, D., O'Reilly, J., \& McGarr, O. (2013). Enhancing the student experiment experience: Visible scientific inquiry through a virtual chemistry laboratory. Research in Science Education, 43(4), 15711592.

ECDL. (2010). ECDL syllabus 5.0. Utrecht: ECDL Nederland NV.

Edgar, L. D., Johnson, D. M., \& Cox, C. (2012). A 10-year assessment of information and communication technology tasks required in undergraduate agriculture courses. Computers \& Education, 59, 741-749.

George, R. (2006,). A cross-domain analysis of change in students' attitudes toward science and attitudes about the utility of science. International Journal of Science Education, 28(6), 571-589.

Goyette, K. A., \& Mullen, A. L. (2006). Who studies the arts and sciences? Social background and the choice and consequences of undergraduate field of study. The Journal of Higher Education, 77(3), 497-538. 
Graham, D. L. (2001). Employer perception of the preparation of agricultural and extension education graduates. Journal of Southern Agricultural Education Research, 51(1), 88-101.

Hohlfeld, T. N., Ritzhaupt, A. D., \& Barron, A. E. (2013). Are gender differences in perceived and demonstrated technology literacy significant? It depends on the model. Educational Technology Research and Development, 61(4), 639-663.

Huggins, A. C., Ritzhaupt, A. D., \& Dawson, K. (2014). Measuring information and communication technology literacy using a performance assessment: Validation of the student tool for technology literacy $\left(\mathrm{ST}^{2} \mathrm{~L}\right)$. Computers \& Education, 77(August), 1-12.

Hsu, H. Y., Wang, S. K., \& Runco, L. (2013). Middle school science teachers' confidence and pedagogical practice of new literacies. Journal of Science Education and Technology, 22(3), 314-324.

Ilomäki, L., Paavola, S., Lakkala, M., \& Kantosalo, A. (2015). Digital competence - an emergent boundary concept for policy and educational research. Education and Information Technologies (in press). Retrieved from http://link.springer.com/article/10.1007/s10639-014-9346-4

Kaminski, K., Switzer, J., \& Gloeckner, G. (2009). Workforce readiness: a study of university students' fluency with information technology. Computers \& Education, 53(2), 228-233.

Kober, N. (2014). Reaching students: What research says about effective instruction in undergraduate science and engineering. Washington: The National Academies Press.

Kubiatko, M. (2010). Czech university students' attitudes towards ICT used in science education. Journal of Technology and Information Education, 2(3), 20-25.

Kubiatko, M., \& Vlckova, K. (2010). The relationship between ICT use and science knowledge for Czech students: a secondary analysis of PISA. International Journal of Science and Mathematics Education, $8(3), 523-543$.

Lai, C., Wang, Q., \& Lei, J. (2012). What factors predict undergraduate students' use of technology for learning? A case from Hong Kong. Computers \& Education, 59(2), 569-579.

Losh, S. C. (2004). Gender, educational, and occupational digital gaps 1983-2002. Social Science Computer Review, 22(2), 152-166.

Mac Callum, K., \& Jeffrey, L. (2013). The influence of students' ICT skills and their adoption of mobile learning. Australasian Journal of Educational Technology, 29(3), 303-3014.

Mac Callum, K., Jeffrey, L., \& Kinshuk. (2014). Comparing the role of ICT literacy and anxiety in the adoption of mobile learning. Computers in Human Behavior, 39(October), 8-19.

Madigan, E. M., Goodfellow, M., \& Stone, J. A. (2007). Gender, perceptions, and reality: technological literacy among first-year students. Proceedings of the 38th SIGCSE Techical Symposium on Computer Science Education (pp. 410-414). New York: ACM. doi: 10.1145/1227310.1227453. Retrieved from http://dl.acm.org/citation.cfm?id=1227310

Mandrikas, A., Parkosidis, I., Psomiadis, P., Stoumpa, A., Chalkidis, A., Mavrikaki, E., \& Skordoulis, C. (2013). Improving pre-service elementary teachers' education via a laboratory course on air pollution: One university's experience. Journal of Science Education and Technology, 22(2), 113-123.

Maneschijn, M. M., Botha, A., \& van Biljon, J. A. (2013). A critical review of ICT skills for higher education learners. International Conference on Adaptive Science and Technology (ICAST), 2013, (pp. 113). Retrieved from $\mathrm{http} / / /$ ieeexplore.ieee.org/xpl/articleDetails.jsp?tp=\&arnumber=6707503\&queryText\%3DManeschijn

Matsui, T., Ikeda, H., \& Ohnishi, R. (1989). Relations of sex-typed socializations to career self-efficacy expectations of college students. Journal of Vocational Behavior, 35, 1-16.

Mead, G. H. (1972). The philosophy of the act. (Seventh Impression ed., Vol. 3). (C. W. Morris, Ed.) Chicago \& London: The University of Chicago Press. 
Mead, G. H. (1974). Mind, self, and society from the standpoint of a social behaviorist. (Nineteenth Impression ed., Vol. 1). (C. W. Morris, Ed.) Chicago \& London: The University of Chicago Press.

Miliszewska, I. (2008). ICT skills: An essential graduate skill in today's global economy. Proceedings of the Informing Science \& IT Education Conference (In SITE) 2008 (pp. 101-109). Retrieved from http://proceedings.informingscience.org/InSITE2008.

Nair, I., \& Das, V. M. (2011). Analysis of recent studies undertaken for assessing acceptance of technology among teachers using TAM. International Journal of Computer Applications, 32(8), 38-45.

Odaci, H. (2013). Risk-taking behavior and academic self-efficacy as variables accounting for problematic Internet use in adolescent university students. Children and Youth Services Review, 35(1), 183-187.

OECD (2015). How is the global talent pool changing $(2013,2030)$ ? In Education indicators in focus. Paris: OECD. Retrieved from http://www.oecd.org/edu/skills-beyondschool/EDIF\%2031\%20\%282015\%29--ENG--Final.pdf

Parsons, T. (1964). The social system. Glencoe, IL: The Free Press.

Pechtelidis, Y., Kosma, Y., \& Chronaki, A. (2015). Between a rock and a hard place: women and computer technology. Gender and Education, 27(2), 164-182.

Prensky, M. (2001). Digital natives, digital immigrants Part 1. On the Horizon, 9(5), 1-6. doi:http://dx.doi.org/10.1108/10748120110424816

Rabaya'h, K. S. (2010). Testing the ICT use correlation with students' academic achievements in math and science based on the TIMMS international test scores. 2nd Conference on Technologies of Information and Communication in Education and Training, (pp. 1-14). Retrieved from https://www.researchgate.net/profile/Khalid_Rabayah2

Ridgewell, J., \& Exley, B. (2011). The potentials of student initiated netspeak in a middle primary scienceinspired multiliteracies project. Research in Science Education, 41(5), 635-649.

Rosseel, Y. (2012). Lavaan: An R package for structural equation modeling. Journal of Statistical Software, 48(2), 1-36.

Russell, D. W., Lucas, K. B., \& McRobbie, C. J. (2003). The role of the microcomputer-based laboratory display in supporting the construction of new understandings in kinematics. Research in Science Education, 33(2), 217-243.

Sadler, P. M., Sonnert, G., Hazari, Z., \& Tai, R. (2012). Stability and volatility of STEM career interest in high school: A gender study. Science Education, 96(3), 411-427.

Schaal, S., Bogner, F. X., \& Girwidz, R. (2010). Concept mapping assessment of media assisted learning in interdisciplinary science education. Research in Science Education, 40(3), 339-352.

Selwyn, N. (1997) Students' attitudes toward computers: Validation of a computer attitude scale for 16-19 education. Computers \& Education, 28(1), 35-41.

Shibutani, T. (1986). Social Processes. An Introduction to Sociology. Berkeley: University of California Press.

Simmel, G. (1910). How is society possible? American Journal of Sociology, 16(3), 372-391. Retrieved from http://www.jstor.org/stable/276309

Smirnov, E., \& Bogun, V. (2010). Science learning with information technologies as a tool for "Scientific Thinking" in engineering education. Natural Science, 2(12), 1400-1406.

Spieza, V. (2011). Does computer use increase educational achievements? Student-level evidence from PISA. OECD Journal: Economic Studies, 2011, 1-22. Retrieved from http://www.oecdilibrary.org/economics/does-computer-use-increase-educational-achievements-student-level-evidencefrom-pisa_eco_studies-2010-5km33scwlvkf 
Summers, T. A., \& Vlosky, R. P. (2001). Technology in the classroom: the LSU College of Agriculture Faculty perspective. Campus-Wide Information Systems, 18(2), 79-84. doi:http://dx.doi.org/10.1108/10650740110386152

Ursavaş, Ö. F., \& Teo, T. (2011). A multivariate analysis of the effect of gender on computer anxiety among elementary school teachers. British Journal of Educational Technology, 42(2), E19-E20.

van Deursen, A. J., \& van Dijk, J. A. (2015). Internet skill levels increase, but gaps widen: A longitudinal cross-sectional analysis (2010-2013) among the Dutch population. Information, Communication \& Society, 18(7), 782-797.

Vekiri, I. (2010a). Socioeconomic differences in elementary students' ICT beliefs and out-of-school experiences. Computers \& Education, 54(4), 941-950.

Vekiri, I. (2010b). Boys' and girls' ICT beliefs: Do teachers matter? Computers \& Education, 55(1), 16-23.

Vekiri, I., \& Chronaki, A. (2008). Gender issues in technology use: Perceived social support, computer self-efficacy and value beliefs, and computer use beyond school. Computers \& Education, 51(3), 13921404.

Venkatesh, V., Morris, M. G., Davis, G. B., \& Davis, F. D. (2003). User acceptance of information technology: toward a unified view. MIS Quarterly, 27(3), 425-478.

Venville, G., Rennie, L., Hanbury, C., \& Longnecker, N. (2013). Scientists reflect on why they chose to study science. Research in Science Education, 43(6), 2207-2233.

Verhoeven, J. C., Heerwegh, D., \& De Wit, K. (2010). Information and communication technologies in the life of university freshmen: An analysis of change. Computers \& Education, 55(1), 53-66.

Volman, M., \& van Eck, E. (2001). Gender equity and information technology in education: the second decade. Review of Educational Research, 71(4), 613-634.

Wang, Y., Wu, M., \& Wang, H. (2009). Investigating the determinants and age and gender differences in the acceptance of mobile learning. British Journal of Educational Technology, 40(1), 92-118.

Zhao, L., Lu, Y., Huang, W., \& Wang, Q. (2010). Internet inequality: The relationship between high school students' Internet. Computers \& Education, 55(4), 1405-1423.

Zhong, Z. J. (2011). From access to usage: The divide of self-reported digital skills among adolescents. Computers \& Education, 56(3), 736-746. 


\section{Appendix}

Model Parameter Values for the Final SEM and Items of Scales (the original items are in Dutch) $(\mathrm{N}=\mathbf{2 6 6})$.

\begin{tabular}{|c|c|c|c|c|c|}
\hline & $\begin{array}{l}\text { Esti- } \\
\text { mate }\end{array}$ & SE & Z-value & $\mathbf{P}(>|z|)$ & $\begin{array}{l}\text { Standardized } \\
\text { Estimate }\end{array}$ \\
\hline \multicolumn{6}{|l|}{ FACTORS and FACTOR Loadings } \\
\hline \multicolumn{6}{|l|}{ MAINTENANCE } \\
\hline V109 I can close a non-responsive program. & 1.000 & & & & 0.640 \\
\hline V110 I can adjust the resolution of my monitor. & 1.653 & 0.305 & 5.418 & 0.000 & 0.708 \\
\hline V111 I can install software. & 1.395 & 0.250 & 5.586 & 0.000 & 0.767 \\
\hline V112 I can make a backup of the data on my hard disk. & 1.669 & 0.371 & 4.494 & 0.000 & 0.594 \\
\hline V113 With the aid of a search tool, I can search for a file on the hard disk. & 1.034 & 0.141 & 7.358 & 0.000 & 0.656 \\
\hline $\begin{array}{l}\text { V114 I can disable programs that run automatically on startup of my PC but } \\
\text { which I do not need. }\end{array}$ & 1.996 & 0.360 & 5.550 & 0.000 & 0.700 \\
\hline V115 I can install a new printer. & 1.440 & 0.296 & 4.861 & 0.000 & 0.632 \\
\hline \multicolumn{6}{|l|}{ WORD } \\
\hline V116 I can put special characters, such as ǔ, $\mathrm{S}, \mathrm{O}, \underset{?}{\underline{i}}$, in my text. & 1.000 & & & & 0.508 \\
\hline V117 I can correct grammatical mistakes using grammar control. & 0.768 & 0.215 & 3.565 & 0.000 & 0.480 \\
\hline V118 I can create a table to display data. & 0.756 & 0.215 & 3.517 & 0.000 & 0.711 \\
\hline V119 I can change the column width or the row height of a table. & 0.810 & 0.173 & 4.674 & 0.000 & 0.711 \\
\hline V120 I can use a text editor to add a background color to a table. & 0.797 & 0.254 & 3.141 & 0.002 & 0.625 \\
\hline V121 I can look up a word in a text file by using the search function. & 0.474 & 0.204 & 2.321 & 0.020 & 0.464 \\
\hline \multicolumn{6}{|l|}{ SPREADSHEET } \\
\hline $\begin{array}{l}\text { V122 With digital spreadsheets I can make simple calculations (addition, } \\
\text { subtraction, multiplication, division). }\end{array}$ & 1.000 & & & & 0.780 \\
\hline $\begin{array}{l}\text { V134 I can work in a digital spreadsheet with some simple functions (Average, } \\
\text { Sum, Round). }\end{array}$ & 1.338 & 0.159 & 8.395 & 0.000 & 0.840 \\
\hline V135 I can enter a formula in a digital spreadsheet. & 1.217 & 0.122 & 9.979 & 0.000 & 0.760 \\
\hline $\begin{array}{l}\text { V123 In a digital spreadsheet program I can enter a new spreadsheet based on } \\
\text { an existing style }\end{array}$ & 1.336 & 0.197 & 6.789 & 0.000 & 0.614 \\
\hline $\begin{array}{l}\text { V124 In a digital spreadsheet I can format the cells so that numbers with a } \\
\text { specific number of decimal digits are displayed. }\end{array}$ & 1.373 & 0.187 & 7.355 & 0.000 & 0.747 \\
\hline V125 I can scale a large spreadsheet so that it prints on a single sheet of paper. & 1.440 & 0.212 & 6.789 & 0.000 & 0.662 \\
\hline V126 I can print a specific part of a table from a digital spreadsheet. & 1.330 & 0.193 & 6.908 & 0.000 & 0.623 \\
\hline $\begin{array}{l}\text { V127 In digital spreadsheets I can make the lines of a table that has to be } \\
\text { printed thicker or thinner. }\end{array}$ & 1.044 & 0.175 & 5.950 & 0.000 & 0.617 \\
\hline V128 I can merge cells in digital spreadsheets. & 1.103 & 0.170 & 6.500 & 0.000 & 0.691 \\
\hline V129 I can hide columns in digital spreadsheets. & 1.330 & 0.206 & 6.448 & 0.000 & 0.590 \\
\hline V133 I can make a print preview of a spreadsheet. & 0.996 & 0.150 & 6.633 & 0.000 & 0.681 \\
\hline V130 I can create a graph in a spreadsheet. & 1.056 & 0.164 & 6.455 & 0.000 & 0.729 \\
\hline
\end{tabular}




\section{ICT skill levels of undergraduate science students}

V131 I can change the graph type in a spreadsheet (e.g., change from a lin

1.158

0.153

7.576

0.000

0.743 graph to a bar graph).

V132 In digital spreadsheets I can add data labels (e.g., scores,\%) to a chart.

1.278

0.187

6.825

0.000

0.727

DATABASE
V136 I can open or close a database.

V137 I can create a new, simple database and put data in it.

1.000

$\begin{array}{lllll}1.010 & 0.025 & 40.084 & 0.000 & 0.966\end{array}$

V138 In a database program I can open a table, a form, or a query.

$\begin{array}{lllll}0.966 & 0.028 & 34.827 & 0.000 & 0.925\end{array}$

V139 In a database program I can add or remove records in a table.

$\begin{array}{lllll}1.024 & 0.027 & 37.757 & 0.000 & 0.983\end{array}$

V140 With a database program I can add a field to a table.

$\begin{array}{lllll}1.009 & 0.028 & 35.626 & 0.000 & 0.976\end{array}$

V141 In a database program I can change the width of the columns in a table.

1.020

0.030

34.274

0.000

0.950

\begin{tabular}{|c|c|c|c|c|c|}
\hline \multicolumn{6}{|l|}{ PRESENTATION } \\
\hline $\begin{array}{l}\text { V144 In a presentation program I can change the column width or row height } \\
\text { of a table. }\end{array}$ & 1.000 & & & & 0.862 \\
\hline V145 In a presentation program I can insert rows or columns in a table. & 0.919 & 0.082 & 11.174 & 0.000 & 0.812 \\
\hline V146 In a presentation program I can enter data to create a chart. & 1.135 & 0.079 & 14.341 & 0.000 & 0.831 \\
\hline V147 In a presentation program I can change the chart type of a graph. & 1.058 & 0.062 & 17.114 & 0.000 & 0.898 \\
\hline $\begin{array}{l}\text { V142 With a presentation program I can insert a different template into a } \\
\text { presentation that primarily works on another template. }\end{array}$ & 0.979 & 0.090 & 10.911 & 0.000 & 0.705 \\
\hline $\begin{array}{l}\text { V143 I can change the position of a slide with the help of the slide sorter of a } \\
\text { presentation program. }\end{array}$ & 0.585 & 0.091 & 6.405 & 0.000 & 0.621 \\
\hline \multicolumn{6}{|l|}{ BROWSER } \\
\hline V149 I can delete cookies from my computer using my web browser. & 1.000 & & & & 0.719 \\
\hline $\begin{array}{l}\text { V150 I can delete temporary Internet files from my computer using my web } \\
\text { browser. }\end{array}$ & 1.036 & 0.059 & 17.461 & 0.000 & 0.741 \\
\hline V152 With a Web browser I can save a web page on my hard drive. & 0.771 & 0.072 & 10.703 & 0.000 & 0.649 \\
\hline $\begin{array}{l}\text { V154 I can translate a website in a foreign language directly into Dutch using a } \\
\text { Web browser. }\end{array}$ & 0.597 & 0.079 & 7.525 & 0.000 & 0.629 \\
\hline V148 With a Web browser I can delete the Web browser history. & 0.524 & 0.082 & 6.409 & 0.000 & 0.676 \\
\hline V151 I can search with a Web browser in an Internet Encyclopedia. & 0.452 & 0.082 & 5.496 & 0.000 & 0.552 \\
\hline V153 With a Web browser I can print an Internet page. & 0.408 & 0.082 & 4.946 & 0.000 & 0.554 \\
\hline \multicolumn{6}{|l|}{ E-COMMUNICATION } \\
\hline $\begin{array}{l}\text { V155 Using a special program I can have a conversation with my partner while } \\
\text { we are both looking at files on his/her and my computer. }\end{array}$ & 1.000 & & & & 0.741 \\
\hline $\begin{array}{l}\text { V156 I can with Voice over IP (e.g., Skype, SIPdiscount, Voiceglobe, etc.) call my } \\
\text { friends even if they do not have Voice over IP. }\end{array}$ & 0.956 & 0.105 & 9.115 & 0.000 & 0.711 \\
\hline $\begin{array}{l}\text { V157 I can create filters to send emails automatically to specific folders (e.g. } \\
\text {,study, football, etc.). }\end{array}$ & 0.698 & 0.096 & 7.265 & 0.000 & 0.532 \\
\hline \multicolumn{6}{|l|}{ SKILLS (Second order factor) } \\
\hline Maintenance & 1.000 & & & & 0.723 \\
\hline Word & 0.684 & 0.191 & 3.584 & 0.000 & 0.492 \\
\hline Spreadsheet & 1.210 & 0.329 & 3.681 & 0.000 & 0.634 \\
\hline Database & 1.848 & 0.546 & 3.382 & 0.001 & 0.404 \\
\hline Presentation & 1.874 & 0.511 & 3.663 & 0.000 & 0.652 \\
\hline Browser & 2.249 & 0.460 & 4.888 & 0.000 & 0.721 \\
\hline
\end{tabular}


Heerwegh, De Wit, \& Verhoeven

\begin{tabular}{|c|c|c|c|c|c|}
\hline E-communication & 2.422 & 0.618 & 3.920 & 0.000 & 0.621 \\
\hline \multicolumn{6}{|l|}{ ANXIETY/BEHAVIOR (Selwyn, 1997) } \\
\hline V158 I hesitate to use a computer because I am afraid to look stupid. & 1.000 & & & & 0.812 \\
\hline V161 Computers make me feel uncomfortable. & 0.757 & 0.138 & 5.489 & 0.000 & 0.443 \\
\hline V166 The prospect of having to use a computer does not scare me at all. & -0.638 & 0.144 & -4.426 & 0.000 & -0.454 \\
\hline V167 I hesitate to use a computer for fear of making mistakes I can't correct. & 0.751 & 0.094 & 8.010 & 0.000 & 0.658 \\
\hline V172 I feel comfortable using a computer. & -0.704 & 0.152 & -4.647 & 0.000 & -0.548 \\
\hline V169 I am not in complete control when I use a computer. & 0.809 & 0.088 & 9.226 & 0.000 & 0.498 \\
\hline V168 I only use computers at college/school when told to. & 0.883 & 0.107 & 8.286 & 0.000 & 0.549 \\
\hline V171 I avoid coming into contact with computers in college/school. & 0.779 & 0.113 & 6.903 & 0.000 & 0.513 \\
\hline V173 I would avoid taking a job if I knew it involved working with computers. & 0.868 & 0.094 & 9.258 & 0.000 & 0.683 \\
\hline \multicolumn{6}{|l|}{ USEFULNESS (Selwyn, 1997) } \\
\hline V160 Computers allow me to do more interesting and imaginative work. & 1.000 & & & & 0.729 \\
\hline V162 Computers help me organize my work better. & 0.851 & 0.097 & 8.771 & 0.000 & 0.569 \\
\hline V163 Computers make it possible to work more productively. & 0.906 & 0.089 & 10.137 & 0.000 & 0.700 \\
\hline $\begin{array}{l}\text { V164 Computers can enhance the presentation of my work to a degree which } \\
\text { justifies the extra effort. }\end{array}$ & 1.020 & 0.094 & 10.815 & 0.000 & 0.791 \\
\hline V165 Most things that a computer can be used for I can do just as well myself. & -0.105 & 0.085 & -1.235 & 0.217 & -0.088 \\
\hline \multicolumn{6}{|l|}{ CONTROL (Selwyn, 1997) } \\
\hline $\begin{array}{l}\text { V159 If I get problems using the computer, I can usually solve them one way } \\
\text { or the other. }\end{array}$ & 1.000 & & & & 0.768 \\
\hline V169 I am not in complete control when I use a computer. & -0.292 & 0.072 & -4.062 & 0.000 & -0.225 \\
\hline V170 I do not need someone to tell me the best way to use a computer. & 0.657 & 0.109 & 6.005 & 0.000 & 0.386 \\
\hline $\begin{array}{l}\text { V174 I could probably teach myself most of the things I need to know about } \\
\text { computers. }\end{array}$ & 0.980 & 0.088 & 11.171 & 0.000 & 0.711 \\
\hline V172 I feel comfortable using a computer. & 0.415 & 0.062 & 6.653 & 0.000 & 0.404 \\
\hline V166 Using a computer does not scare me at all. & 0.360 & 0.078 & 4.592 & 0.000 & 0.321 \\
\hline \multicolumn{6}{|l|}{ ICT SCIENCE } \\
\hline V200 Today, a scientific researcher cannot work properly without a computer. & 1.000 & & & & 0.480 \\
\hline $\begin{array}{l}\text { V201 A scientific researcher must be able to properly work with a word pro- } \\
\text { cessor. }\end{array}$ & 1.430 & 0.234 & 6.101 & 0.000 & 0.802 \\
\hline $\begin{array}{l}\text { V202 A scientific researcher must be able to properly work with a digital } \\
\text { spreadsheet. }\end{array}$ & 1.449 & 0.233 & 6.221 & 0.000 & 0.762 \\
\hline $\begin{array}{l}\text { V203 A scientific researcher must be able to properly work with a presenta- } \\
\text { tion program. }\end{array}$ & 1.484 & 0.249 & 5.968 & 0.000 & 0.748 \\
\hline V204 A scientific researcher should be good at working with a databases. & 1.124 & 0.244 & 4.614 & 0.000 & 0.612 \\
\hline $\begin{array}{l}\text { V205 A scientific researcher must be able to properly work with a drawing } \\
\text { program. }\end{array}$ & 0.768 & 0.175 & 4.395 & 0.000 & 0.366 \\
\hline $\begin{array}{l}\text { V206 A scientific researcher should be good at working with databases on the } \\
\text { Internet. }\end{array}$ & 0.633 & 0.202 & 3.136 & 0.002 & 0.375 \\
\hline $\begin{array}{l}\text { V207 A scientific researcher must be able to keep in touch with his colleagues } \\
\text { using the Internet. }\end{array}$ & 1.082 & 0.220 & 4.926 & 0.000 & 0.665 \\
\hline V208 A scientific researcher must be able to solve basic computer problems & 1.189 & 0.260 & 4.577 & 0.000 & 0.561 \\
\hline
\end{tabular}


ICT skill levels of undergraduate science students

Regressions:

\begin{tabular}{|c|c|c|c|c|c|}
\hline SKILLS ON & & & & & \\
\hline Anxiety/Behavior & -0.082 & 0.046 & -1.770 & 0.077 & -0.172 \\
\hline Usefulness & 0.083 & 0.032 & 2.562 & 0.010 & 0.208 \\
\hline Control & 0.321 & 0.070 & 4.597 & 0.000 & 0.846 \\
\hline ICT science & 0.120 & 0.054 & 2.233 & 0.026 & 0.171 \\
\hline Age PC started & 0.016 & 0.009 & 1.700 & 0.089 & 0.123 \\
\hline \multicolumn{6}{|l|}{ ANXIETY/BEHAVIOR ON } \\
\hline Age PC started & 0.049 & 0.013 & 3.675 & 0.000 & 0.184 \\
\hline \multicolumn{6}{|l|}{ USEFULNESS ON } \\
\hline Age PC started & -0.078 & 0.022 & -3.603 & 0.000 & -0.244 \\
\hline \multicolumn{6}{|l|}{ CONTROL ON } \\
\hline female & -0.619 & 0.100 & -6.215 & 0.000 & -0.381 \\
\hline Age PC started & -0.119 & 0.018 & -6.445 & 0.000 & -0.353 \\
\hline \multicolumn{6}{|l|}{ ICT SCIENCE ON } \\
\hline Age PC started & -0.033 & 0.015 & -2.264 & 0.024 & -0.182 \\
\hline \multicolumn{6}{|l|}{ Covariances: } \\
\hline V149 WITH V150 & 0.503 & 0.115 & 4.370 & 0.000 & 0.633 \\
\hline V130 WITH V131 & 0.151 & 0.071 & 2.123 & 0.034 & 0.447 \\
\hline Maintenance with browser & 0.127 & 0.036 & 3.512 & 0.000 & 0.684 \\
\hline V204 WITH V206 & 0.198 & 0.036 & 5.540 & 0.000 & 0.477 \\
\hline
\end{tabular}

$\mathrm{R}^{2}$ values: ICT skills: 0.81; Anxiety/Behavior: 0.03; Usefulness: 0.06; Control: 0.30; ICT Science: 0.03 


\section{Biographies}

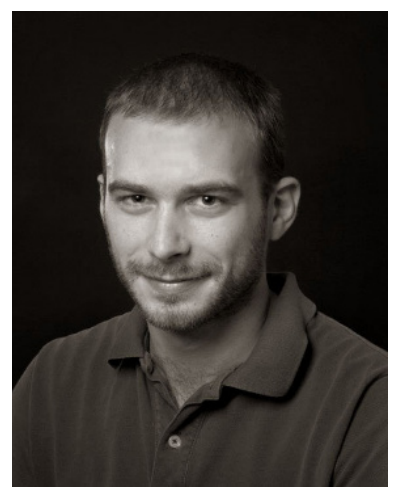

Dirk Heerwegh is professor of statistics at the University of Leuven (Belgium) and a senior manager statistical programming at Janssen Pharmaceuticals (Belgium). In 2005, he obtained his $\mathrm{PhD}$ in the field of social survey methods at the University of Leuven (Belgium). His academic publications are in the fields of survey methodology, attitudes towards Europe, and the use of ICT. He teaches a statistical course on structural equation modeling and has previously taught courses on data management, survey research methods, and various courses in applied statistics.

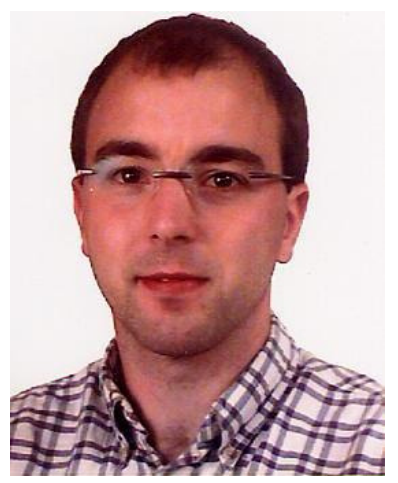

Kurt De Wit, PhD in Sociology, is head of the Data Management Unit of the Education Policy and Quality Department at the University of Leuven (KU Leuven) in Belgium. In that function he carries out institutional research regarding students and education and monitors national and European higher education policy. He also serves on the Executive Council of the Flemish Sociological Association and was editor-in-chief of its peer-reviewed journal (2010-2013). His current research interests include education innovation policy in higher education, the roles of ICT for university students, international rankings of higher education institutions, governance and funding of higher education, and the development of the network society and its consequences for higher education. His most recent publications include papers in Computers and Education, Education and Information Technologies, and the European Educational Research Journal.

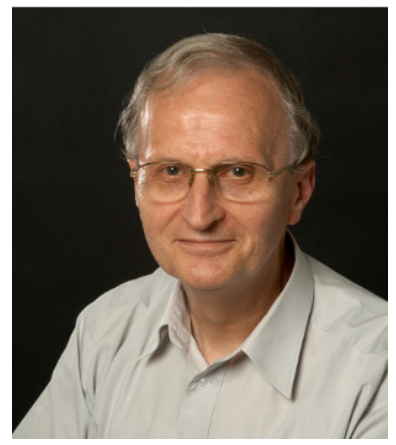

Jef C. Verhoeven is emeritus professor of sociology at the University of Leuven (Belgium). He has been teaching sociological theory and sociology of education at the University of Leuven and abroad (https://perswww.kuleuven.be/ u0003309/School/EducationAndTheor $\mathrm{y} /$ indexhoogGuestE css.html). He published numerous articles and books in the fields of theoretical sociology and sociology of education (http://www.researchgate.net/profile/Jef Verhoeven). His recent research is focused on higher education, the use of ICT, and inequality of educational opportunities 